\title{
High Influence of Potassium Bromide on Thermal Decomposition of Ammonia Borane ${ }^{\dagger}$
}

\author{
Nikola Biliškov, ${ }^{a}$ Danijela Vojta, ${ }^{a}$ László Kótai, ${ }^{b}$ Imre Miklós Szilágyi, ${ }^{c, d}$ Dávid Hunyadi, ${ }^{c}$ Tibor \\ Pasinszki, ${ }^{e}$ Sandra Flinčec Grgac, ${ }^{f}$ Andreas Borgschulte ${ }^{g}$ and Andreas Züttel ${ }^{g, h}$
}

\begin{abstract}
The present work presents a thorough experimental investigation of mechanistic pathways of thermal decomposition of ammonia borane $(\mathrm{AB})$ and its mixture with $\mathrm{KBr}$. A comparative detection and temperature-dependent in-situ monitoring of the decomposition products was done by use of temperature dependent infrared (IR) spectroscopy of both solid (in transmission through KBr pellets and ATR mode) and gaseous products, thermogravimetry (TG) and evolved gas analysis mass spectroscopy (EGA-MS). This enables discrimination of the processes occuring in the bulk from those in the near-surface level. For the first time, a high influence of the $\mathrm{KBr}$ matrix on $\mathrm{AB}$ decomposition was found and thoroughly investigated. Although $\mathrm{KBr}$ does not change the chemical and physical identity of $\mathrm{AB}$ at ambient conditions, it dramatically affects its thermal decomposition pathway. It is found that the presence of $\mathrm{KBr}$ not only favours the production of diammoniate of diborane in the induction phase, but also enables an efficient catalysis of $\mathrm{AB}$ decomposition by $\mathrm{NH}_{4}^{+}$ions, present at the $\mathrm{KBr}-\mathrm{AB}$ interface, which leads to suppression of emission of unwanted gaseous side products other than $\mathrm{NH}_{3}$. IR spectroscopy was also used to shed a light on the molecular background of the frequently observed, but never investigated increase of the mass of decomposition products.
\end{abstract}

\section{Introduction}

Ammonia borane $\left(\mathrm{NH}_{3} \mathrm{BH}_{3}\right.$, further in the text denoted as $\left.\mathrm{AB}\right)$ and its derivatives continue to attract widespread attention as a perspective family of materials for solid-state hydrogen storage, ${ }^{1,2}$ due to their extremely high both gravimetric and volumetric hydrogen capacity (19.6 wt.\% and $145 \mathrm{~g} \mathrm{~cm}^{3}$, respectively), a moderate dehydrogenation temperature and stability at ambient conditions. However, the drawbacks for its use include long induction period for dehydrogenation at $85^{\circ} \mathrm{C}$, release of unwanted

\footnotetext{
${ }^{0 a}$ Rudjer Bošković Institute, Bijenička c. 54, Zagreb, Croatia. Tel: +3851456 1084; E-mail: nikola.biliskov@irb.hr

${ }^{0 b}$ Institute of Materials and Environmental Chemistry, Research Centre for Natural Sciences, Hungarian Academy of Sciences, Budapest, Hungary

${ }^{0 c}$ Department of Inorganic and Analytical Chemistry, Budapest University of Technology and Economics, Müegyetem rakpart 3, Szent Gellért tér 4, Budapest, Hungary.

${ }^{0 d}$ MTA-BME Technical Analytical Chemistry Research Group, Szent Gellért tér 4, Budapest, Hungary.

${ }^{0 e}$ Department of Inorganic Chemistry, Eötvös Lorand University of Sciences, Budapest, Hungary.

${ }^{0 f}$ Faculty of Textile Technology, University of Zagreb, Savska c. 16/9.

${ }^{0} \mathrm{~g}$ Swiss Fedaral Institute for Materials Science and Technology (EMPA), Überlandstrasse 129, Dübendorf, Switzerland.

${ }^{0 h}$ Laboratory of Materials for Renewable Energy (LMER), Institute of Chemical Sciences and Engineering (ISIC), École polytechnique de Lausanne (EPFL), Valais/Wallis Energypolis, Rue de l'industrie 17, CH-1950 Sion, Switzerland.
} 
side-products and exothermic thermodynamics, leading to stable products that are mainly unable to rehydrogenate. Additionally, $\mathrm{AB}$ and its derivatives follow very complicated dehydrogenation pathways, ${ }^{3-5}$ which are still not satisfactorily understood.

A crucial prerequisite for all of the above mentioned issues is to elucidate the mechanistic details of thermal decomposition of $\mathrm{AB}$, as well as structural changes of $\mathrm{AB}$ during these processes. In this respect, a special attention is targeted to lower the dehydrogenation temperature, to supress the release of unwanted side products and to find out an energy-efficient regeneration process for the spent fuel. Thus, a considerable experimental and theoretical efforts were performed in this respect. ${ }^{1-24}$ Baumann et al. ${ }^{6}$ have followed thermal decomposition of polyaminoboranes (PAB) by combined thermal and spectroscopic measurements. On the other hand, Frueh et al. used a combination of ex-situ IR spectroscopy and thermogravimetry/differential thermal analysis, coupled with mass spectroscopy (TG/DTA-MS) to record and assign solid and gas-phase products of thermal dehydrogenation of $\mathrm{AB}$, as obtained at 120,210 and $1500{ }^{\circ} \mathrm{C}$, respectively. ${ }^{7}$ Dehydrogenation of $\mathrm{AB}$ is extensively investigated by in-situ solidstate ${ }^{11}$ B NMR spectroscopy. ${ }^{8-11}$ Key intermediates of dehydrogenation process are detected by Shaw et al., ${ }^{11}$ allowing the authors to propose a mechanism. Their findings are highly consistent with in-depth high-level theoretical study by Zimmerman et al., ${ }^{4,5}$ published simultaneously, but independently. By investigating the role of $\mathrm{NH}_{2} \mathrm{BH}_{2}$ in oligomerisation of the products of decomposition, authors proposed and explored a number of intermediates and reaction pathways. In a recent publication, Kobayashi et al. used a combination of ${ }^{11} \mathrm{~B}$ and ${ }^{15} \mathrm{~N}$ NMR spectroscopy to successfuly resolve the species that appear at different temperatures between 100 and $200{ }^{\circ} \mathrm{C} .{ }^{13}$ Miranda and Ceder considered thermodynamics and vibrational spectra of AB decomposition by DFT on the basis of a simple model of two mechanistic pathways; the first leads toward linear and another toward cyclic polymers. ${ }^{12} \mathrm{~A}$ comparative analysis of $\mathrm{AB}$ dehydrogenation in solution and in gas phase, given more recently by the Zimmerman's group, indicates considerably different reaction pathways in considered media. ${ }^{5}$ Especially important is their consideration of formation of ionic species diammoniate of diborane (DADB), which is feasible in solution phase, particularly in polar media. However, it is shown that the final products will be the same, and explainable by rapid oligomerization of $\mathrm{NH}_{2} \mathrm{BH}_{2}$ monomers, irrespectively if DADB is formed at the initial stage or not.

Vibrational spectoscopies are frequently used to investigate thermolysis of $\mathrm{AB}$ and its derivatives. Among them, IR spectroscopy is especially popular due to its simplicity and high availability, together to its richness in information. ${ }^{25-27}$ Additionally, IR spectra of various potential products of decomposition of $\mathrm{AB}$, such as cyclic oligoaminoboranes, ${ }^{28-30}$ polymeric aminoborane, ${ }^{31-33}$ borazine ${ }^{34}$ and polyborazylene ${ }^{35}$ are described. However, routinely used transmission IR spectroscopy should be done with a due care, in order to avoid misleading results. A more attentive inspection of published spectra reveals a rather widespread methodological inadvertence and a rather uncritical insight into recorded spectra (Table S1). In some cases, the use of $\mathrm{KBr}$ as a diluting matrix leads to serious misinterpretations of the IR spectra. Strictly speaking, before accepting an IR spectrum, measured by transmission of IR light through $\mathrm{KBr}$ pellet, its validity should be ascertained by other independent methods. Among all publications which deal with IR spectroscopy of $\mathrm{AB}$, some discussion on matrix-initiated spectral variations is found only in 
those by Taylor and Jash. ${ }^{36,37}$ Another commonly used technique of recording IR spectra is attenuated total reflection (ATR). However, one must be aware that the spectra obtained by the two techniques are not necessary equal, since the optical setup of ATR gives an information on near-surface level of the sample under consideration, depending on the nature of the sample. ${ }^{38,39}$

Since the published IR spectra are frequently rather incosistent, and since an increase of the sample mass during TG measurements after the initial expected drop is frequently observed, but never satisfactory discussed, ${ }^{7,40}$ here we address the following questions: 1 . Is there any influence of $\mathrm{KBr}$ on thermal decomposition of $\mathrm{AB}$ ? 2. Are the thermally induced processes the same in the bulk and on the near-surface layer of AB? 3. What is the composition of the solid and gas-phase products? 4. Are the crucial intermediates of thermal decomposition of $\mathrm{AB}$ detectable by spectroscopic methods? 5 . What is the background of the frequently observed increase of the mass of $\mathrm{AB}$ decomposition products? In this respect, we have employed IR spectroscopy as a central experimental method to study the changes in solid-state and gas phase products due to thermal dehydrogenation of AB. As a support, TG/DTA and TG/DTA-MS are also employed.

To the best of our knowledge, this is the first comprehensive study of the effect of $\mathrm{KBr}$ to decomposition of $\mathrm{AB}$. Additionally, the combination of transmission with ATR IR spectroscopy allowed us to resolve the changes at the near-surface level with those in the bulk of the sample. The present results open a route to design and a series of composites with significantly improved hydrogen storage properties, based on $\mathrm{AB}$ and alkali halides,

\section{Experimental}

Only a general remarks on experimental procedures employed during this study are given here. A detailed description of all experiments can be found in ESI.

We used the two most common methods of IR spectroscopic measurements of solid samples, namely transmission through $\mathrm{KBr}$ pellet and single-reflection attenuated total reflection (ATR). We used it for both in situ monitoring of thermal decomposition, as well as to follow the changes in decomposition products over time. These measurements were compared with thermogravimetry/differential thermal analysis (TG/DTA). In this respect, the same heating rate $\left(2^{\circ} \mathrm{Cmin}^{-1}\right)$ was applied for IR and TG/DTA measurements. The pellets for transmission measurements were prepared by mixing of the sample of $\mathrm{AB}$ with $\mathrm{KBr}$.

Hereafter in the text, the samples are denoted as $\mathbf{X}-\mathbf{y} . \mathbf{1}$ denotes neat $\mathrm{AB}, \mathbf{2}$ is a $\mathrm{KBr}$ pellet of $\mathrm{AB}$ for transmission IR spectroscopy and $\mathbf{3}$ is $1: 1$ (molar ratio) mixture of $\mathrm{AB}$ with $\mathrm{KBr}$. System 3 is used as a model of the mixture of $\mathrm{AB}$ with $\mathrm{KBr}$ appropriate for acquisition of ATR IR spectra, since intensities in ATR spectra of $\mathbf{2}$ are very low making these spectra unusable. The second part of the symbol, i.e. $\mathbf{y}$ indicates the dehydrogenation temperature in ${ }^{\circ} \mathrm{C}$ at which the particular product is obtained. 


\section{Results}

As seen in Fig. 1 (a), powder XRD of system 3 at room temperature can be roughly described as a linear combination of diffractograms for system 1 and KBr. IR and Raman spectra (Figs. 1(b) and (c)) are identical for neat AB and its mixtures with $\mathrm{KBr}$, even after prolonged ball milling, which altogether proves that the chemical and physical identity of $\mathrm{AB}$ remains intact at ambient conditions irrespective of conditions in which samples are prepared (see ESI, sections S4 and S5). However, the XRD lines are slightly broadened and shifted relative to the original positions, which can be explained by a change in crystallite size and lattice parameters due to the grinding of the mixture.

Thermogravimetric analysis (TG) If only $\mathrm{H}_{2}$ is released from the sample, the mass drop would be $6.5 \%$ per individual decomposition step. However, it is evident from Fig. 2 that all the samples show a significantly bigger drop of the mass over the first step.

Table 1 lists the processes detectable by TG/DTA. For $\mathbf{1}$, TG shows insensitivity of the $1^{\text {st }}$ step of thermolytic process to the atmosphere, i.e. exactly the same drop of the mass is observed in both air and $\mathrm{N}_{2}$ (Fig. 2). For 3, decomposition in both air and $\mathrm{N}_{2}$ leads to a single-step mass loss, exactly as expected for release of 2 equivalents of $\mathrm{H}_{2}$, although this obviously does not mean that only $\mathrm{H}_{2}$ is released.

DTA also shows that for both systems the first decomposition step is not very sensitive to atmosphere. However, the second step is more pronounced in air with respect of $\mathrm{N}_{2}$. Also, the second decomposition step is reflected by a more pronounced DTA signal for 1, which is in accordance with TG, but also with variable-temperature IR (Fig. 3).

Infrared spectra (IR) The observed room-temperature IR spectra of all the three considered systems are shown in Fig. 1 (b) and characteristic bands are listed in Table 2. The assignation is argumented in details in ESI, section S3.1. Spectra remain almost intact bellow $105^{\circ} \mathrm{C}$, when first significant changes occur. Above this temperature, changes in IR spectra are dramatic in all aspects, as described in section S8.1.

In-situ temperature-dependent IR spectra, obtained during the course of this study, are presented in Fig. 3, while Table 3 lists changes in most representative bands. Temperature-induced changes in positions of IR bands due to the stretching modes are presented in Fig. S26.

$\boldsymbol{T G}$-IR The native gas-phase IR spectra are presented in Figs. S34 and S35. They show features due to $\mathrm{NH}_{3}$ at 930 and $966 \mathrm{~cm}^{-1}$ (most intense rotational lines of $v_{2}$ mode), $v(\mathrm{BH})$ at $2530 \mathrm{~cm}^{-1}$ (attributed to borazine due to its high correlation with corresponding EGA-MS signals) and $1230 \mathrm{~cm}^{-1}$ band. The main trends in intensities of these bands are given in Fig. 4. A detailed description of IR spectra of gas-phase decomposition products is given in section S8.2.

TG/DTA-MS Mass spectra revealed that a number of species are released during the decomposition process (Fig. 5, Tables 4 and 5). The most intense signals are due to $\mathrm{H}_{2}, \mathrm{NH}_{3}$, cyclo- $\left(\mathrm{NH}_{2} \mathrm{BH}_{2}\right)_{2}$ and cyclo-(NHBH$)_{3}$ (borazine). Furthermore, these species are $\sim 20 \times$ more abundant in the case of $\mathbf{1}$ with respect of $\mathbf{3}$ (Table 5), indicating an interaction of this species with 
$\mathrm{KBr}$, which deters it in solid state. EGA-MS for system 1 shows additional signals of low intensity at $\mathrm{m} / z=44$ and 59 , not present for 3. They indicate the possible presence of $\mathrm{BH}\left(\mathrm{NH}_{2}\right)_{2}$ and $\mathrm{B}\left(\mathrm{NH}_{2}\right)_{3}$, respectively. ${ }^{41}$ It is evident that release of $\mathrm{H}_{2}$ occurs simulteneously with $\mathrm{NH}_{3}$. Although they are mainly released after melting, a minor amount of these species is released $<100^{\circ} \mathrm{C}$, which coincides with occurence of the cyclo- $\left(\mathrm{NH}_{2} \mathrm{BH}_{2}\right)_{2}$. It is important to note that the same amounts of $\mathrm{H}_{2}$ and $\mathrm{NH}_{3}$ are released for $\mathbf{1}$ and $\mathbf{3}$, while borazine and cyclo- $\left(\mathrm{NH}_{2} \mathrm{BH}_{2}\right)_{2}$ emissions are largely supressed for $\mathbf{3}$.

Changes in solid-state decomposition products An increase of the mass of products $X-150$ and $\mathbf{X - 2 0 0}(\mathbf{X}=\mathbf{1}$ or 3$)$ by exposure to air or $\mathrm{N}_{2}$ is observed (Fig. S10). As evident, practically the same curves are observed in all cases. Time-dependent IR monitoring of the samples $X-125, X-150$ and $X-200(X=1,2,3$, see Figs. S16-S24) indicate development of various species with respect of the temperature of production, but significant differences are observed in near-surface and bulk processes. The $m / m_{0}=f(t)$ changes are well correlated with increase of the $v(\mathrm{NH})$ and $v(\mathrm{BH})$ bands at near-surface level of $\mathbf{X}-\mathbf{1 2 5}$ systems (Fig. S14). The PIB $v(\mathrm{NH})$ feature at $3440 \mathrm{~cm}^{-1}$ is observed for all X-150 systems, as well as 2-200. Significantly lower intensity band for 1-150 indicates a lower temperature of PIB formation when $\mathrm{AB}$ is mixed with $\mathrm{KBr}$. This band remains practically intact during the exposure to air in all cases.

\section{Discussion}

IR spectra of $\mathbf{1}$ and $\mathbf{3}$ are recorded by ATR technique, while $\mathbf{2}$ by transmission. Dimensions of the AB powder particles, as measured by optical microscope, are between 200 and $600 \mu \mathrm{m}$. Thus, the penetration depth of the incident IR light in ATR experiment of $d_{p} \leq 2 \mu \mathrm{m}$ allows consideration of these spectra in terms of near-surface processes. This means that IR spectra of $\mathbf{1}$ and $\mathbf{3}$ reflect processes in the near-surface level, while those of $\mathbf{2}$ contain a combined information on both near-surface and the bulk. However, since the pathlength of the IR radiation through the bulk of the sample is incomparably longer than through the near-surface level, the information on the bulk is predominant in a transmission experiment.

Since $\mathrm{KBr}$ matrix could affect $\mathrm{AB}$, it is crucial to resolve if the observed differences are due to $\mathrm{KBr}$ or some other effects. It is evident that at ambient conditions the chemical and physical identity of $\mathrm{AB}$ remains intact, and the samples $\mathbf{2}$ and $\mathbf{3}$ are mere physical mixtures of $\mathrm{AB}$ and $\mathrm{KBr}$ (Fig. 1 and Table S3). Although there are slight differences between ATR spectrum of 1 and transmission spectrum of $\mathbf{2}$, especially in the $1300-1000 \mathrm{~cm}^{-1}$ region, the ATR spectra for $\mathbf{1}$ and $\mathbf{3}$ are practically the same. Thus, the observed differences are due to optical background of the ATR and transmission experiment, respectively.

Some inconsistencies in assignation of IR bands to vibrational modes are found in the literature, especially in the $1400-$ $1150 \mathrm{~cm}^{-1}$ region. The bands at $1380 \mathrm{~cm}^{-1}$ and $1165 \mathrm{~cm}^{-1}$ are, on the basis of extensive vibrational analysis, attributed to outof-plane $\delta\left(\mathrm{NH}_{3}\right)$ and $\delta\left(\mathrm{BH}_{3}\right)$ (umbrella) mode, respectively. ${ }^{42-44}$ On the other hand, in frequently cited paper by Baumann $e t$ $a l$. these bands are tentatively assigned to $v(\mathrm{BN})+\delta_{\text {out-of-plane }}\left(\mathrm{NH}_{3}\right)$ combination $\left(1380 \mathrm{~cm}^{-1}\right)$ and $\tau\left(\mathrm{BH}_{3}\right)\left(1165 \mathrm{~cm}^{-1}\right) .{ }^{6}$ The observed high similarity in temperature-induced behaviour of these bands (Fig. S30) is consistent with assignation of the first 
group of authors, so further in the text we adopt the assignation for $\mathrm{AB}$ as proposed by Hess et al. ${ }^{44} \mathrm{IR}$ spectra of the number of individual species that are expected to be produced during the $\mathrm{AB}$ decomposition process can be found in literature. However, since the decomposition products are complex mixtures of various species in intermolecular interaction, the observed spectra of the products cannot be considered as a mere linear composition of the spectra of individual species. Additionally, fingerprint region is highly dependent on various conformational differences of the products of thermal decomposition, such as cis-trans isomerism, degree of crystallinity, exact stoichiometry, branching, existence and amount of cyclic structural motives etc. All of this disables a straightforward and accurate assignation of the IR spectra of decomposition products.

Further discussion is divided into three main parts, with respect to the $\mathrm{AB}$ decomposition steps. Although this allows a clearer organization of the text, the reader must be aware that these processes does not occur separately over the temperature coordinate, so they cannot be strictly considered independently to each other.

\section{Induction phase}

Roughly speaking, the induction phase consists of formation of DADB as a key intermediate species that directs the pristine system towards decomposition, over a number of crucial physical and chemical changes. ${ }^{30}$

The chemical identity of $\mathrm{AB}$ is radically changed during this phase, and this process is significantly faster in the bulk of AB lumps. For $\mathbf{1}$, these processes occur simultaneously with emission of cyclo-diaminoborane (CDAB) and $\mu$-aminodiborane ( $\mu \mathrm{ADB}$ ) or their isomers, showing a significance of formation of initial $\mathrm{NH}_{2} \mathrm{BH}_{2}$ in solid state and its immediate reaction with DADB. ${ }^{4}$ The amount of these species is very low, but comparable with $\mathrm{H}_{2}$ released in this phase (Fig. 5). In the case of $\mathbf{3}$, even a smaller amount of CDAB was observed without a traces of $\mu \mathrm{ADB}$ (Table 4). Thus, decomposition of $\mathbf{1}$ can be satisfactorily modeled by a combined consideration of formation of both cyclic and linear polymers, ${ }^{12}$ having in mind that the two mechanistic pathways are not independent, but mutually entangled since the starting species are equal. ${ }^{4}$

A complete absence of these species is observed in the case of $\mathbf{3}$. It seems that in $\mathbf{3}$, the produced intermediates are consumed by interaction with $\mathrm{KBr}$, disabling their observation in the gas phase. More importantly, this interaction pushes the further reaction to an alternate mechanistic pathway. Time-dependent NMR measurements reveal the evolution of cyclic PAB species from DADB at $95^{\circ} \mathrm{C} .{ }^{11}$ In the first stage $\mathrm{CDAB}$ is produced, which reacts with $\mathrm{AB}$ giving $B$-(cyclodiborazanyl)amino-borohydride (BCDB) and finally its isomer cyclotriborazane $\mathrm{N}_{3} \mathrm{~B}_{3} \mathrm{H}_{12}$ (CTB). EGA-MS indicates that the system enters the $1^{\text {st }}$ decomposition step with a significant amount of cyclic species, that react mutually and with remaining DADB, in accordance with evidences from ab initio calculations ${ }^{4}$ and experiments. $6,7,11,40$

A similar behaviour is observed in the case of $v(\mathrm{BN})$ mode at $782 \mathrm{~cm}^{-1}$, accompanied by $v\left({ }^{10} \mathrm{BN}\right)$ at $797 \mathrm{~cm}^{-1}$. The band completely disappears during the induction phase, as evident from Fig. 6(a). This is synchronised with start of $\mathrm{H}_{2}$ release, which confirms the evidence from kinetic analysis that the activation energy of the dehydrogenation is equal to the strength of 
$\mathrm{B} \rightarrow \mathrm{N}$ dative bond. ${ }^{45}$ Apparently, DADB is formed under non-isothermal conditions through two mechanisms, the first acting near the surface, and another in the bulk. The isothermal measurements clearly show that the release of $\mathrm{H}_{2}$ in this temperature range follows nucleation-and-growth mechanism. ${ }^{30}$ Temperature dependence of the IR intensity of $\rho\left(\mathrm{NH}_{3}\right), \rho\left(\mathrm{BH}_{3}\right)$ and $v(\mathrm{BN})$ for systems 1 and 3 show a maximum at $85^{\circ} \mathrm{C}$, while the $v_{\text {as }}(\mathrm{BH})$ reaches a maximum as low as $75^{\circ} \mathrm{C}$, indicating the equal near-surface process in these two systems. This is further supported by observation of neighbour band at $725 \mathrm{~cm}^{-1}$, assigned to $\rho\left(\mathrm{BH}_{3}\right)$ mode (Fig. 6(b)), as well as $\rho\left(\mathrm{NH}_{3}\right)$ at $1060 \mathrm{~cm}^{-1}$. However, the maximum is less pronounced for system $\mathbf{3}$, and it is reached at a slightly lower temperature with respect of $\mathbf{1}$. Ionic matrix $\mathrm{KBr}$ supports formation of DADB, while the relaxed dihydrogen bonding network, characteristic for expanded lattice of $\mathrm{AB}$, is critically required for formation of DADB. Thus, it is clear that an interplay between $\mathrm{KBr}$ and formation of intermediate phase of $\mathrm{AB}$ in $\mathbf{3}$ takes place. The more pronounced effect of $\mathrm{KBr}$ in $\mathbf{2}$ is in accordance with this trend, indicating that the apparent mechanistic difference is due to the effect of $\mathrm{KBr}$. The $I(t)$ curve of $v(\mathrm{BN})$ band brakes at $85^{\circ} \mathrm{C}$, i.e. The observed significant intensification of the $\rho\left(\mathrm{BH}_{3}\right)$ band in this temperature region can be explained by a transition of $\mathrm{AB}$ into an expanded lattice, ${ }^{30}$ resulting in a significant change of molecular dynamics within the crystal lattice and related weakening of ${ }^{\delta+} \mathrm{H} \cdots \mathrm{H}^{\delta-}$ dihydrogen bonding network. The increased precession of $\mathrm{AB}$ molecules around $\mathrm{B}-\mathrm{N}$ bond facilitates dimerisation into DADB, which becomes a predominant process above $85^{\circ} \mathrm{C}$. After this maximum, the intensity of the bands steeply drop to zero, indicating the solid-state reorganization accompanied by formation of new species, that follow to decomposition of the samples. On the other hand, for $\rho\left(\mathrm{NH}_{3}\right)$ band a relatively regular behavior, i.e. the behavior similar to the considered bands for all the three systems, is evident. The continuous $I(t)$ curves throughout the induction phase simply reflect that in mixture 2 , where $\mathrm{AB}$ is well dispersed in a large excess of $\mathrm{KBr}(\mathrm{AB}: \mathrm{KBr} \approx 1: 100)$, $\mathrm{DADB}$ formation starts as low as $50{ }^{\circ} \mathrm{C}$, whenever a small quantities of $\mathrm{AB}$ suffered an expansion of the cell. Significantly different behavior of the $\rho\left(\mathrm{BH}_{3}\right)$ mode of sample 2 indicates that the above discussed processes occur mainly near surface, while $\mathrm{BH}_{3}$ groups suffer a significant changes in the bulk.

Both $v_{\mathrm{as}}(\mathrm{NH})$ and $v_{\mathrm{as}}(\mathrm{BH})$ for $\mathbf{2}$ and $\mathbf{3}$ continuously drop in intensity following a simple behaviour over the induction phase. However, for these two systems, a significant deviation from TG curve is evident (Fig. 7). In the low temperature region, i.e. below $50{ }^{\circ} \mathrm{C}$, practically equal behaviour of all the three systems was observed. Slight, but indicative changes of $v(\mathrm{BH})$ envelope are well correlated with disappearance of $v(\mathrm{BN})$ and $\rho\left(\mathrm{BH}_{3}\right)$ bands. Obviously, intensity of the $v(\mathrm{BH})$ region does not significantly decrease during the induction phase, since it terminates prior than any significant breaking of $\mathrm{B}-\mathrm{H}$ bonds take place. Qualitatively, the intensity of $v(\mathrm{BH})$ envelope behaves in all details equal to above described bands. For $2, v(\mathrm{BH})$ is slightly shifted toward the higher wavenumbers with a simultaneous increase of the band width accompanied by a significant broadening of the $v(\mathrm{NH})$ region at temperatures above $85^{\circ} \mathrm{C}$, which is not observed in the case of $\mathbf{1}$ and $\mathbf{3}$. This reflects the formation of ionic species DADB, accompanied by a significant redistribution of electron density, that consequently causes a strengthening of hydrogen bonding in the bulk. The $\left[\left(\mathrm{NH}_{3}\right)_{2} \mathrm{BH}_{2}\right]^{+}$ions of neat DADB are arranged differently in solid state with respect to 
$\left[\left(\mathrm{NH}_{3}\right)_{2} \mathrm{BH}_{2}\right]^{+} \mathrm{Cl}^{-}, 46$ leading to a significant changes in dihydrogen bonding network. This suggests that $\left[\left(\mathrm{NH}_{3}\right)_{2} \mathrm{BH}_{2}\right]^{+} \mathrm{Br}^{-}$ ionic pairs, that are expected to emerge at the interface between $\mathrm{AB}$ and $\mathrm{KBr}$ phase simultaneously with formation of DADB, disturb the dihydrogen bonding network and consequently change the molecular dynamics of the system.

The predominant change in baseline absorption of the variable temperature IR spectra of 2 (Fig. S32) is exclusively caused by the process occuring in the $85-105^{\circ} \mathrm{C}$ region, centered at $95^{\circ} \mathrm{C}$, which preceeds melting. This is attributed to formation of DADB, ${ }^{46}$ enforced by its interaction with $\mathrm{K}^{+}$and $\mathrm{Br}^{-}$ions at the $\mathrm{AB}-\mathrm{KBr}$ interface. Although no clear evidence of DADB formation can be found in IR spectra, ${ }^{28,47}$ the rise of baseline absorption occurs simultaneously with appearance of the $3160 \mathrm{~cm}^{-1}$ band in $v(\mathrm{NH})$ region of both $\mathbf{2}$ and $\mathbf{3}$, and a moderate shift of $v(\mathrm{BH})$ absorption to higher wavenumbers with appearance of a weak band at $2360 \mathrm{~cm}^{-1}$. Further, a broadening of the 3160 and $1380 \mathrm{~cm}^{-1}$ band can be attributed to enhancement of the hydrogen bonding by formation of DADB inside AB lumps. The observed spectral changes can be explained by solid-state ionic reaction of DADB with KBr matrix, further accelerated by melting of AB. For sure, the ionic exchange between DADB and $\mathrm{KBr}$ significantly influences the mechanistic pathway for $\mathrm{AB}$ decomposition in $\mathbf{2}$ and $\mathbf{3}$, which is reflected in differences observed in spectra of their further decomposition relative to those of $\mathbf{1}$.

The $1380 \mathrm{~cm}^{-1}$ and $725 \mathrm{~cm}^{-1}$ features are attributed to out-of-plane $\delta\left(\mathrm{NH}_{3}\right)$ (umbrella) and $\rho\left(\mathrm{BH}_{3}\right)$ mode, respectively. ${ }^{44}$ A Gaussian bandshape, as a consequence of inhomogeneous band broadening mechanism, indicates that these vibrations are affected by inhomogeneities and fluctuations in the microscopic structure of the sample, as a consequence of hydrogen bonding, which causes different local environment of the absorbing particles. Intensity of these bands significantly drops above $100{ }^{\circ} \mathrm{C}$, with simultaneous rise of new high-temperature broad features at very close positions. Appearance of these new features disables an accurate fitting of the pristine bands, but it is clear that they disappear due to decomposition of $\mathrm{AB}$.

Melting of $\mathbf{1}$ starts at $110^{\circ} \mathrm{C}$, which is reflected in endothermic DSC and DTA peak that reaches its minimum at $115^{\circ} \mathrm{C}$ (Figs. 2 and S43). As evident from TG, decomposition starts simultaneously, i.e. melting is accompanied with drop of the mass, which is explained in the light of enhanced mobility of the reacting species in the liquid phase, which triggers the massive dehydrogenation. System 3 melts at $5{ }^{\circ} \mathrm{C}$ lower temperature, i.e. at $105^{\circ} \mathrm{C}$. However, TG shows a somewhat slower decomposition until AB is completely melted at $110^{\circ} \mathrm{C}$. IR spectra of 1-100 and 3-100 approximatelly correspond to those of the pristine systems (Fig. S6). On the other hand, 2-100 is significantly changed, especially in the $v(\mathrm{NH})$ region, which is broadened with simultaneous rise of the feature centered at $3150 \mathrm{~cm}^{-1}$.

As a summary, during the induction phase of decomposition, $\mathrm{AB}$ completely dimerize into DADB, which is indicated in IR spectra by a complete disappearance of bands due to $\rho\left(\mathrm{BH}_{3}\right)$ and $\rho\left(\mathrm{NH}_{3}\right)$ modes. Simultaneous disappearance of $v(\mathrm{BN})$ mode indicates a significant change of distribution of electron density and thus the nature of $\mathrm{B}-\mathrm{N}$ bond. At the final stages of induction phase it starts to react with $\mathrm{NH}_{2} \mathrm{BH}_{2}$, which initiates decomposition, still very inefficient in solid state. Higher mobility of the species, ensured by transition into the liquid state by melting, further enforces decomposition, and the system enters the 
$1^{\text {st }}$ decomposition step.

\section{$1^{\text {st }}$ decomposition step}

Phase transition of the system to liquid state enables free movement of individual molecules thus enforcing autocatalytic action of $\mathrm{NH}_{2} \mathrm{BH}_{2} \cdot{ }^{4}$ The melting of $\mathrm{AB}$ and the formation of initial quantities of intermediate species $\mathrm{NH}_{2} \mathrm{BH}_{2}$ is followed by its efficient polymerisation to a complex mixture of higher oligomers and polymers, both linear and cyclic, under a general name PAB. As a direct consequence, this step is characterised by an intense release of $\mathrm{H}_{2}$ in a relatively narrow temperature range (see Fig. 5).

EGA-MS clearly shows that, together with $\mathrm{H}_{2}, \mathrm{NH}_{3}$ contribute to the mass loss for $\mathbf{3}$ in the same amount as for $\mathbf{1}$. However, 1 also releases borazine and a trace of diborane $\mathrm{B}_{2} \mathrm{H}_{6}$ (Fig. 5, S21), contained only in a trace quantity for 3. This indicates a substantial change of mechanistic pathway of $\mathrm{AB}$ decomposition by addition of $\mathrm{KBr}$ to the system. Due to its highly polar character, melted $\mathrm{AB}$ can partially solve $\mathrm{KBr}$, giving rise to contact ionic pairs that redirect the reaction pathway and supresses the formation of $\mathrm{B}_{2} \mathrm{H}_{6}$, borazine and other side-products.

Different from previously published observations, ${ }^{6,7}$ solid-state IR spectra obtained in this temperature range does not show any significance of features that could be attributed to terminal $\mathrm{NH}_{2}$ groups of linear polyaminoborane (PAB). Thus, $\mathbf{X}-\mathbf{1 2 0}$ samples consist exclusively of single bonded amorphous PAB species, consisting mainly of tetrahedral, single bonded $\mathrm{N}$ and B atoms. ${ }^{6}$ The individual polymeric products could not be resolved by here employed methods, since linear, branched and cyclic PAB species have a very similar IR spectra. However, a comparison of X-120 with calculated spectra ${ }^{12}$ indicates a predominance of CTB as a product of the $1^{\text {st }}$ step, in agreement with NMR findings. ${ }^{11}$ Only a few features, i.e. the bands centered at 2284 , 1154 and $700 \mathrm{~cm}^{-1}$, can be undoubtedly assigned to linear polymeric PAB species. Their formation is only slightly preferred for 1. DFT calculations indicate a formation of linear $\mathrm{BH}_{3} \mathrm{NH}_{2} \mathrm{BH}_{2} \mathrm{NH}_{3}$ together with $\mathrm{CDAB}$ dimers as a key intermediates in the initial steps of $\mathrm{AB}$ decomposition that preferably both lead to formation of CTB. ${ }^{4}$

Both $v(\mathrm{NH})$ and $v(\mathrm{BH})$ regions suffer a significant changes in this phase of $\mathrm{AB}$ decomposition (Fig. 3). The complex $v(\mathrm{NH})$ region of all the three systems change with development of broad and unresolved envelopes. As expected, their intensity decrease simultaneously with mass loss observed by TG (Fig. 7). Obviously, a broad $v(\mathrm{NH})$ feature indicates a reorganization of initial hydrogen bonding into an extensive heterogeneous intermolecular network in the liquid state. 1-125 and 3-125 show an additional prominent shoulder at $3280 \mathrm{~cm}^{-1}$, which does not exist in the case of $\mathbf{2 - 1 2 5}$, indicating a different organization in the near-surface layer with respect of the bulk. On the other hand, although the changes in $v(\mathrm{BH})$ envelope for $\mathbf{1}$ follow the behavior of $v(\mathrm{NH})$, the changes in $v(\mathrm{BH})$ region for 2 are limited exclusively to drop of intensity of $v_{\mathrm{s}}(\mathrm{BH})$ and $v_{\mathrm{as}}(\mathrm{BH})$ band, while no significant change of this feature is observed for $\mathbf{3}$. For all the three systems, a delayed response of the mass loss with respect of all stretching vibrations is evident (Fig. 7). However, this effect is significantly less expressed for $\mathbf{1}$ and $v(\mathrm{BN})$ for $\mathbf{1}$ and $\mathbf{3}$ (Fig. 6). Also, a notably very tight correlation of $\delta\left(\mathrm{NH}_{3}\right)$ and TG for $\mathbf{1}$ is observed. However, mutually rather similar behavior 
is observed for the other two systems (Fig. 7), indicating a substantial changes in underlying processes when $\mathrm{AB}$ is mixed with $\mathrm{KBr}$.

The intensity of the $1605 \mathrm{~cm}^{-1}$ band, attributed to $\delta\left(\mathrm{NH}_{3}\right)$ vibration (Fig. 7, Table S3) drops, disappearing in the same manner for 2 and 3. Slow intensity drop is observed over the whole $25-90^{\circ} \mathrm{C}$ range, when it becomes steeper, and the band completely disappears at $125^{\circ} \mathrm{C}$. For $\mathbf{1}$ no drop is observed below $105^{\circ} \mathrm{C}$, and its decomposition actually ends at temperature as high as $160^{\circ} \mathrm{C}$. Simultaneously with disappearance of this band, the $1560 \mathrm{~cm}^{-1}$ band appears, which is attributed to intermediate PAB species (Fig. 8). Although the position and behavior of the $1560 \mathrm{~cm}^{-1}$ band corresponds to cycloborazane species, ${ }^{29}$ our spectra do not allow undoubtful assignation of this band. Thus, this feature might be attributed to species represented by general formula cyclo $-\left(\mathrm{NH}_{2} \mathrm{BH}_{2}\right)_{n}$. Obviously, cyclo $-\left(\mathrm{NH}_{2} \mathrm{BH}_{2}\right)_{3}$ is thermodynamically preferred species, but it is clear that in present conditions a formation of a mixture composed of numerous species, including linear and branched, is much more probable.

The corresponding $\delta\left(\mathrm{BH}_{3}\right)$ feature is found at $1160 \mathrm{~cm}^{-1}$. The intensity of this band drops simultaneously with $\rho(\mathrm{NBH})$ band for all the three systems. In the case of $\mathbf{2}$ and $\mathbf{3}$ all the bands remain well resolved, indicating maintenance of ordering even in liquid state. The ordering of the system $\mathbf{3}$ is governed by interaction of surface polar molecules with $\mathrm{KBr}$. This interaction shifts the $\delta\left(\mathrm{BH}_{3}\right)$ band by $+10 \mathrm{~cm}^{-1}$ above $105^{\circ} \mathrm{C}$. For $\mathbf{1}$, this band becomes completely unresolved by development of a broad and very intense envelope peaking at $1140 \mathrm{~cm}^{-1}$, which is attributed to products of oxidation near the surface.

For all the three systems the appearance of a broad feature peaking at $\sim 1240 \mathrm{~cm}^{-1}$ is evident above $105^{\circ} \mathrm{C}$. System 2 clearly shows appearance of an additional band at $1125 \mathrm{~cm}^{-1}$, while for the other two systems we could only assume the existence of this band, which is supported by the temperature dependence of absorption at this wavenumber. On the basis of observed isosbestic points in the case of 2 and behavior of these features with respect of the bands of the pristine system, we assign the $1240 \mathrm{~cm}^{-1}$ and $1125 \mathrm{~cm}^{-1}$ to PAB modes $\delta\left(\mathrm{BH}_{2}\right)$ and $\rho(\mathrm{NBH})$, respectively. Fig. 8 shows a more readily formation of this intermediate species for 1 . TG-IR indicate that the species formed at this stage at least partially react with $\mathrm{NH}_{3}$ and then evaporate, which will be discussed in more details further in the text. This assumption is further supported by monitoring of temporal evolution of solid products X-125 (Figs. S16-S18), which clearly show a decrease in intensity at $1250 \mathrm{~cm}^{-1}$ simultaneous with a rise of $1390 \mathrm{~cm}^{-1}$ absorption. This is also correlated with increasing features due to $\mathrm{NH}$ groups. Altogether, this indicates a partial decomposition of $\mathrm{PAB}$ to a gaseous product by reaction with $\mathrm{NH}_{3}$.

\section{$2^{\text {nd }}$ decomposition step}

Above $120^{\circ} \mathrm{C}$, gaseous products, namely ammonia $\mathrm{NH}_{3}$, monomeric aminoborane $\mathrm{NH}_{2} \mathrm{BH}_{2}$ and borazine $(\mathrm{NHBH})_{3}$ in addition to hydrogen were recognised by comparison of IR and MS spectra. ${ }^{6,40,48}$ This implies that under the present experimental conditions the formation of PAB ends in this temperature region. However, a large difference in intensity of the $1450 \mathrm{~cm}^{-1}$ band 
(i.e. relatively low intensity of this band as observed in the present work) indicates that in the present conditions highly branched or cyclic PAB species are preferably formed.

Fig. 2 reveals a high influence of the atmosphere on second decomposition step of $\mathbf{1}$, leading to a significantly greater mass loss than expected for release of pure $\mathrm{H}_{2}$. EGA-MS reveals the release of $\mathrm{NH}_{3}$, borazine, diaminoborane $\left(\mathrm{NH}_{2} \mathrm{BH}_{2}\right)_{2}$ and species at 49 and $67 \mathrm{amu}$, together with several additional signals. TG shows a considerably lower mass loss when the $\mathbf{1}$ is heated in air with respect of $\mathrm{N}_{2}$. However, mass spectroscopy shows that the species are released in the same amount irrespective of the atmosphere. This indicates a partial compensation of the mass loss in air, probably by adsorption of some air components or partial oxidation. Comparison of IR spectra of the $\mathbf{X}-\mathbf{1 5 0}$ systems heated over an prolonged time with in-situ spectra shows that PIB production is favored in inert $\mathrm{N}_{2}$ atmosphere. The corresponding bands at $3440 \mathrm{~cm}^{-1}$ and $2500 \mathrm{~cm}^{-1}$ rise with heating time in $\mathrm{N}_{2}$. The process is more efficient in the bulk with respect of the near-surface level. Weighing of the $\mathbf{X}-\mathbf{1 5 0}$ products in air shows a continuous increase of the mass over time, ending at $\left.m / m_{0} \approx 110 \%\right) m_{0}$. Since a very broad feature around $1350 \mathrm{~cm}^{-1}$ increase over time in air, and since this behavior is clearer expressed near the surface, it is assigned to oxidation of the product.

TG-IR shows evidence of release of $\mathrm{NH}_{3}$ and a species represented by $1230 \mathrm{~cm}^{-1}$ band for both $\mathbf{1}$ and $\mathbf{3}$ (Fig. 4). 1 shows an additional $v(\mathrm{BH})$ feature, attributed to borazine. For 3 these events occur over the temperature range of the $1^{\text {st }}$ step, while for 1 these species are detected mainly in the $140-170^{\circ} \mathrm{C}$ region. This indicates that $2^{\text {nd }}$ decomposition step is unresolved from the $1^{\text {st }}$ for 3 .

All the three observed TG-IR features for 3 evolve equally in the $105-119^{\circ} \mathrm{C}$ region, when 930 and $966 \mathrm{~cm}^{-1}$ reach the maximum (Fig. 4(b)). $1230 \mathrm{~cm}^{-1}$ feature continues to increase up to $130{ }^{\circ} \mathrm{C}$, when it reaches the plateau value, twice as high as maximal intensity for the other two bands. For $1,1230 \mathrm{~cm}^{-1}$ band somewhat delays with respect of $\mathrm{NH}_{3}$ and borazine bands (Fig. 4(a)). After a slight fracture at $156^{\circ} \mathrm{C}$, it continues to increase up to $170^{\circ} \mathrm{C}$, when it reaches a plateau. This is explained by a relatively high abundance of the $m / z=81$ species in the gaseous products of $\mathbf{1}$. Significant reaction with ammonia starts at $146^{\circ} \mathrm{C}$ when the intensity of $2530 \mathrm{~cm}^{-1}$ band reaches its maximum and begins to drop. This indicates the production of diaminoborane $\mathrm{BH}\left(\mathrm{NH}_{2}\right)_{2}$ and possible triaminoborane $\mathrm{B}\left(\mathrm{NH}_{2}\right)_{3}$ by reaction ${ }^{41}$

$$
\mathrm{N}_{3} \mathrm{~B}_{3} \mathrm{H}_{6}+3 \mathrm{NH}_{3} \longrightarrow 3 \mathrm{BH}\left(\mathrm{NH}_{2}\right)_{2}
$$

EGA-MS detects these two species only as very low intensity signals for $\mathbf{1}$, indicating that they readily enter a further reaction. The absence of these signals in the EGA-MS, as well as the $2530 \mathrm{~cm}^{-1}$ signal in TG-IR spectra of $\mathbf{3}$ indicates that all of this reactivity occurs in solid state, which is allowed by a presence of $\mathrm{NH}_{4} \mathrm{Br}$ species that originate during induction phase. This also explains why the discussed IR features occur in a relatively low temperature range. A very intense $\mathrm{m} / z=81$ signal for 1 and its absence for 3 in the $>140^{\circ} \mathrm{C}$ region further supports the proposed action of $\mathrm{NH}_{3}$. Finally, the behaviour of $1250 \mathrm{~cm}^{-1}$ band and its correlation with absorption at $1393 \mathrm{~cm}^{-1}$, attributed to $\mathrm{BH}\left(\mathrm{NH}_{2}\right)_{2},{ }^{49}$ show that this reaction is significantly more 
preffered for $\mathbf{2}$ with respect of $\mathbf{1}$. IR monitoring of the temporal evolution of solid products X-150 (Figs. S19-S21) does not show any evidence of changes in absorption at $1250 \mathrm{~cm}^{-1}$, indicating a termination of the reaction by elimination of the second equivalent of $\mathrm{H}_{2}$. Altogether, the behaviour of $I(t)$ profile of $1230 \mathrm{~cm}^{-1}$ band of TG-IR spectra indicates an efficient reaction of $\mathrm{NH}_{3}$ with boron-containing species, produced by decomposition of $\mathrm{AB}$. Volatile $\mathrm{NH}_{3}$ containing species readily react with solid phase giving polyborazylene. For $\mathbf{3}$, this transformation is catalyzed by present $\mathrm{NH}_{4}^{+}$ions and goes directly from $\mathrm{AB}$, thus avoiding formation of borazine in significant amounts. In the case of $\mathbf{1}$, polyborazylene is formed from PAB.

Above $140^{\circ} \mathrm{C}$, the main spectral changes include decrease and, at $200^{\circ} \mathrm{C}$ almost complete disappearance of both $v(\mathrm{NH})$ and $v(\mathrm{BH})$ features, which is consistent with formation of polyiminoborane (PIB) species and finally $\mathrm{NBH}_{\mathrm{y}}$ (where $y \leq 2$ ). For 2, only a moderate changes are observed in the whole $120-200^{\circ} \mathrm{C}$ region. Qualitatively, both $v(\mathrm{NH})$ and $v(\mathrm{BH})$ regions remain almost unchanged, although they continuously decrease in intensity, and the $3430 \mathrm{~cm}^{-1}$ band appears as a weak feature. Simultaneously, a broad envelope peaking at $1415 \mathrm{~cm}^{-1}$ continuously rise in intensity. The rest of fingerprint region is intact (both qualitatively and quantitatively) in the whole temperature region. This indicates formation of stable boranes, that disappear only after a prolonged heating above $200^{\circ} \mathrm{C}$.

On the other hand, spectra of 3 indicate dramatic changes in the $120-140^{\circ} \mathrm{C}$ region. $v(\mathrm{NH})$ and $v(\mathrm{BH})$ regions are broadened, while in the fingerprint region good resolved bands at $1164 \mathrm{~cm}^{-1}$ and $1057 \mathrm{~cm}^{-1}$ merge in a broad envelope. Although it evidently consists of the features characteristic for both $\mathbf{1}$ and $\mathbf{2}$, they are unresolved. Simultaneously, two bands appear, peaking at $1568 \mathrm{~cm}^{-1}$ and at $1400 \mathrm{~cm}^{-1}$. Above $160{ }^{\circ} \mathrm{C}$, the broad unresolved feature in the $1320-940 \mathrm{~cm}^{-1}$ region drops with simultaneous increase of the feature peaking at $1400 \mathrm{~cm}^{-1}$. As discussed above in the text, this is explained by a partial oxidation of the products, which results in numerous bands overlapped with features due to developing BN.

Finally, at $200^{\circ} \mathrm{C}$ the whole fingerprint region of $\mathbf{2}$ and $\mathbf{3}$ become qualitatively equal, while that for $\mathbf{1}$ is rather different. However, after a similar evolution, $v(\mathrm{BH})$ region for $\mathbf{1}$ and $\mathbf{3}$ ends in a rather broad band peaking at $1980 \mathrm{~cm}^{-1}$ and relatively good defined one at $2147 \mathrm{~cm}^{-1} \cdot v(\mathrm{NH})$ band evolves similarly for $\mathbf{2}$ and $\mathbf{3}$. A comparison of $i n$-situ IR spectra for X-200 products shows that a majority of the observed features can be explained by processes in the near-surface level. Qualitatively equal $v(\mathrm{NH})$ region for $\mathbf{1}$ and $\mathbf{2}$ indicates a similar organisation of $\mathrm{NH}$ groups in the bulk of $\mathbf{2}$ with respect of $\mathbf{1}$. However, 1-200 shows relatively more intense $3440 \mathrm{~cm}^{-1}$ band with respect of 2-200 and 3-200, indicating a partial suppression of PIB production in the presence of $\mathrm{KBr}$.

IR monitoring of all the products of prolonged heating indicate that above $200{ }^{\circ} \mathrm{C}$ the majority of the product is converted into boron nitride. In-situ variable temperature IR spectra show that PIB still exists near the surface, while the corresponding bands disappear when the product is exposed to a prolonged heating. In the bulk, no evidence of PIB $v(\mathrm{NH})$ band is found in in-situ variable temperature IR spectra, and $v(\mathrm{BH})$ region is represented by several bands. 


\section{Conclusions}

$\mathrm{KBr}$ does not influence the chemical and physical identity of neat $\mathrm{AB}$ by itself. However, it dramatically affects its thermal decomposition. The three investigated systems undergo rather different decomposition pathways. Although some processes are affected in solid state, pronounced changes occur by melting of $\mathrm{AB}$ and consequent partial solvation of $\mathrm{KBr}$. These processes lead decomposition of $\mathrm{AB}-\mathrm{KBr}$ mixtures to a significantly different mechanistic pathway with respect to neat $\mathrm{AB}$. This is reflected in their different temperature-dependent evolution, as evident from all the employed experimental methods.

The central process of the induction phase of $\mathrm{AB}$ decomposition is its dimerisation into DADB accompanied by a significant redistribution of electron density and thus the nature of $\mathrm{B}-\mathrm{N}$ bond, which is well reflected in IR spectra. Thermally induced development of DADB is significantly supported by the presence of the ionic species such as $\mathrm{KBr}$. At this stage, $\mathrm{NH}_{2} \mathrm{BH}_{2}$ is produced in minor amounts, which causes a release of minor amounts of $\mathrm{H}_{2}$ even before melting of $\mathrm{AB}$. The produced short-living $\mathrm{NH}_{2} \mathrm{BH}_{2}$ reacts with DADB, resulting in several intermediate species, such as CDAB, $\mu \mathrm{ADB}$ and BCDB. They initiate decomposition, still very slow and inefficient in solid state. These species are not detected in emissions accompanied to decomposition of $\mathbf{3}$, which is explained by an efficient ion exchange between $\mathrm{KBr}$ and DADB.

The emission of $\mathrm{CDAB}$ and $\mu \mathrm{ADB}$, respectively, is practically terminated by melting. A higher mobility of the present intermediate species, ensured by transition into the liquid state, enforces decomposition by triggering the fast processes in the melt, which cause polymerisation to $\mathrm{PAB}$ family of species accompanied by a massive release of $\mathrm{H}_{2}$, together with side products, such as ammonia, borazine etc. On the other hand, dehydrogenation, catalysed by the $\mathrm{NH}_{4}^{+}$ions, present at the $\mathrm{KBr}-\mathrm{AB}$ interface in systems $\mathbf{2}$ and $\mathbf{3}$, allows an efficient release of $\mathrm{H}_{2}$ without a substantial emission of side-products other than $\mathrm{NH}_{3}$. The presence of $\mathrm{KBr}$ also causes that $2^{\text {nd }}$ step of dehydrogenation is irresolved from the $1^{\text {st }}$ and it occurs over a significantly broader temperature region with respect of $\mathbf{1}$.

The combination of ATR and transmission IR spectra indicates significantly different processes in the near-surface level with respect of those in the bulk of the considered samples during their thermal decomposition. IR spectra clearly show the changes in decomposition products when exposed to the air. However, the molecular background of these processes, that could be responsive for increase of their masses, was not further investigated in the framework of this study.

Summary, all the crucial intermediate species are directly or indirectly detectable by IR spectroscopy. The present findings, together with theoretical results ${ }^{4,5}$ outline a direction for further experimental and theoretical research, which could lead to improved AB-based systems for solid-state hydrogen storage. The influence, similar to that of $\mathrm{KBr}$, is also expected for the other alkali halides, which opens an opportunity for further optimisation and development of novel, efficient composites based on highly available materials. 


\section{Associated content}

\section{Supporting Information}

Experimental procedures; comments on acquisition of IR spectra; reports on IR spectra of AB and related systems; characteristic IR features and factor group analysis; temperature- and pressure dependent IR spectra; temperature-dependent Raman spectra; EGA-MS; TG/DTA; DSC; powder XRD.

\section{Acknowledgements}

Part of this work was supported by the COST Action MP1103 "Nanostructured materials for solid-state hydrogen storage". NB thanks Dr. Tea Zubin Ferri from Metris, Pula, Croatia. NB also owes the appreciation to ResearchGate, which was an interface that enabled a fruitful collaboration with Hungarian part of the team, but also a useful discussion with Samuel Frueh. IMS thanks a János Bolyai Research Fellowship of the Hungarian Academy of Sciences and an OTKA-PD 109129 grant. DV thanks "Center of excellence for advanced materials and sensing devices” of the Rudjer Bošković Institute for facility utilization. We should not forget a number of other researchers, who also helped this study in a various ways.

NB dedicates this paper to his father who passed away during the completion of this manuscript.

\section{References}

[1] Staubitz, A.; Robertson, A. P. M.; Manners, I. Ammonia Borane and Related Compounds as Dihydrogen Sources Chem. Rev. 2010, 110, 4079-4124.

[2] Graetz, J.; Wolstenholme, D.; Pez, G.; Klebanoff, L.; McGrady, S.; Cooper, A. Hydrogen Storage Technology - Materials and Applications. In ; Klebanoff, L., Ed.; CRC Press, Taylor \& Francis Group: Boca Raton, 2013; Chapter Development of Off-Board Reversible Hydrogen Storage Materials, pages 239-328.

[3] Al-Kukhun, A.; Hwang, H. T.; Varma, A. Mechanistic Studies of Ammonia Borane Dehydrogenation Int. J. Hydrogen En. 2013, 38, 169-179.

[4] Zimmerman, P. M.; Paul, A.; Zhang, Z.; Musgrave, C. B. Oligomerization and Autocatalysis of NH2BH2 with AmmoniaBorane Inorg. Chem. 2009, 48, 1069-1081.

[5] Zimmerman, P. M.; Zhang, Z.; Musgrave, C. B. Dynamic Mechanisms for Ammonia Borane Thermolysis in Solvent: Deviation from Gas-Phase Minimum-Energy Pathways J. Phys. Chem. Lett. 2011, 2, 276-281. 
[6] Baumann, J.; Baitalow, F.; Wolf, G. Thermal Decomposition of Polymeric Aminoborane (H2BNH2)x under Hydrogen Release Thermochim. Acta 2005, 430, 9 - 14.

[7] Frueh, S.; Kellett, R.; Mallery, C.; Molter, T.; Willis, W. S.; Kingondu, C.; Suib, S. L. Pyrolytic Decomposition of Ammonia Borane to Boron Nitride Inorg. Chem. 2011, 50, 783-792.

[8] Wang, J. S.; Geanangel, R. A. 11B $\{$ NMR $\}$ Studies of the Thermal Decomposition of Ammoniaborane in Solution Inorg. Chim. Acta 1988, 148, 185-190.

[9] Bluhm, M. E.; Bradley, M. G.; Butterick III, R.; Kusari, U.; Sneddon, L. G. Amineborane-Based Chemical Hydrogen Storage: Enhanced Ammonia Borane Dehydrogenation in Ionic Liquids J. Am. Chem. Soc. 2006, 128, 7748-7749.

[10] Stowe, A. C.; Shaw, W. J.; Linehan, J. C.; Schmid, B.; Autrey, T. In Situ Solid State 11B MAS-NMR Studies of the Thermal Decomposition of Ammonia Borane: Mechanistic Studies of the Hydrogen Release Pathways from a Solid State Hydrogen Storage Material Phys. Chem. Chem. Phys. 2007, 9, 1831-1836.

[11] Shaw, W. J.; Linehan, J. C.; Szymczak,; Heldebrant, D. J.; Yonker, C.; Camaioni, D. M.; Baker, R. T.; Autrey, T. In Situ Multinuclear NMR Spectroscopic Studies of the Thermal Decomposition of Ammonia Borane in Solution Angew. Chem. Int. Ed. 2008, 47, 7493-7496.

[12] Miranda, C. R.; Ceder, G. Ab Initio Investigation of Ammonia Borane Complexes for Hydrogen Storage J. Chem. Phys. 2007, 126, 184703.

[13] Kobayashi, T.; Gupta, S.; Caporini, M. A.; Pecharsky, V. K.; Pruski, M. Mechanism of Solid-State Thermolysis of Ammonia Borane: A 15N NMR Study Using Fast Magic-Angle Spinning and Dynamic Nuclear Polarization J. Phys. Chem. C 2014, 118, 19548-19555.

[14] Stephens, F. H.; Pons, V.; Baker, R. T. Ammonia Borane: The Hydrogen Source par Excellence? Dalton Trans. 2007, 2613-2626.

[15] Stephens, F.; Baker, R.; Matus, M. H.; Grant, D.; Dixon, D. Acid Initiation of Ammonia Borane Dehydrogenation for Hydrogen Storage Angew. Chem. Int. Ed. 2007, 46, 746-749.

[16] Marder, T. . Will We Soon Be Fueling our Automobiles with Ammonia Borane? Angew. Chem. Int. Ed. 2007, 46, 81168118.

[17] Smythe, N. C.; Gordon, J. C. Ammonia Borane as a Hydrogen Carrier: Dehydrogenation and Regeneration Eur. J. Inorg. Chem. 2010, 509-521. 
[18] Hamilton, C. W.; Baker, R. T.; Staubitz, A.; Manners, I. B-N Compounds for Chemical Hydrogen Storage Chem. Soc. Rev. 2009, 38, 279-293.

[19] Kathmann, S. M.; Parvanov, V.; Schenter, G. K.; Stowe, A. C.; Daemen, L. L.; Hartl, M.; Linehan, J.; Hess, N. J.; Karkamkar, A.; Autrey, T. Experimental and Computational Studies on Collective Hydrogen Dynamics in Ammonia Borane: Incoherent Inelastic Neutron Scattering J. Chem. Phys. 2009, 130, 024507.

[20] Heldebrant, D. J.; Karkamkar, A.; Hess, N. J.; Bowden, M.; Rassat, S.; Zheng, F.; Rappe, K.; Autrey, T. The Effects of Chemical Additives on the Induction Phase in Solid-State Thermal Decomposition of Ammonia Borane Chem. Mater. 2008, 20, 5332-5336.

[21] Nguyen, M. T.; Nguyen, V. S.; Matus, M. H.; Gopakumar, G.; Dixon, D. A. Molecular Mechanism for H2 Release from BH3NH3, Including the Catalytic Role of the Lewis Acid BH3 J. Phys. Chem. A 2007, 111, 679-690.

[22] Nguyen, V. S.; Matus, M. H.; Grant, D. J.; Nguyen, M. T.; Dixon, D. A. Computational Study of the Release of H2 from Ammonia Borane Dimer (BH3NH3)2 and Its Ion Pair Isomers J. Phys. Chem. A 2007, 111, 8844-8856.

[23] Neiner, D.; Luedtke, A.; Karkamkar, A.; Shaw, W.; Wang, J.; Browning, N. D.; Autrey, T.; Kauzlarich, S. M. Decomposition Pathway of Ammonia Borane on the Surface of Nano-BN J. Phys. Chem. C 2010, 114, 13935-13941.

[24] Liang, Y.; Tse, J. S. First-Principles Study on the Mechanisms for H2 Formation in Ammonia Borane at Ambient and High Pressure J. Phys. Chem. C 2012, 116, 2146-2152.

[25] Biliškov, N. Infrared Spectroscopy: Theory, Developments and Applications. In ; Cozzolino, D., Ed.; Nova Publishers: New York, 2014; Chapter Infrared Spectroscopy as a Convenient Tool for Investigation of Hydrogen Sorption Mechanisms and Bonding in Complex Hydrides, pages 343-382.

[26] Paolone, A.; Teocoli, F.; Sanna, S.; Palumbo, O.; Autrey, T. Temperature Dependence of the Infrared Spectrum of Ammonia Borane: Librations, Rotations, and Molecular Vibrations J. Phys. Chem. C 2013, 117, 729-734.

[27] Weismiller, M.; Wang, S.; Chowdhury, A.; Thynell, S.; Yetter, R. Confined Rapid Thermolysis Studies of Ammonia Borane Thermochim. Acta 2013, 551, 110-117.

[28] Carpenter, J. D.; Ault, B. S. Infrared Matrix Isolation Characterization of Aminoborane and Related Compounds J. Phys. Chem. 1991, 95, 3502-3506.

[29] Böddeker, K. W.; Shore, S. G.; Bunting, R. K. Boron-Nitrogen Chemistry. I. Syntheses and Properties of New Cycloborazanes, (BH2NH2)n1,2 J. Am. Chem. Soc. 1966, 88, 4396-4401. 
[30] Bowden, M.; Autrey, T. Characterization and Mechanistic Studies of the Dehydrogenation of NHxBHx Materials Curr. Opin. Solid State Mater. Sci. 2011, 15, 73 - 79.

[31] Kwon, C. T.; McGee, H. A. Cryochemical Preparation of Monomeric Aminoborane Inorg. Chem. 1970, 9, $2458-2461$.

[32] Komm, R.; Geanangel, R. A.; Liepins, R. Synthesis and Studies of Poly(aminoborane), (H2NBH2)x Inorg. Chem. 1983, $22,1684-1686$.

[33] Kim, D.-P.; Moon, K.-T.; Kho, J.-G.; Economy, J.; Gervais, C.; Babonneau, F. Synthesis and Characterization of Poly(aminoborane) as a New Boron Nitride Precursor Polym. Adv. Technol. 1999, 10, 702-712.

[34] Kaldor, A.; Porter, R. F. Matrix Isolation Study of Borazine and Boroxine. Vibrational Analysis Inorg. Chem. 1971, 10, 775-785.

[35] Fazen, P. J.; Remsen, E. E.; Beck, J. S.; Carroll, P. J.; McGhie, A. R.; Sneddon, L. G. Synthesis, Properties, and Ceramic Conversion Reactions of Polyborazylene. A High-Yield Polymeric Precursor to Boron Nitride Chem. Mater. 1995, 7, 1942-1956.

[36] Taylor, R. C. Vibrational Frequencies, Assignments, and Force Constants for Some Compounds Containing Boron-Nitrogen Dative Bonds Adv. Chem. Ser. 1964, 42, 59-70.

[37] Jash, P.; Meaux, K.; Trenary, M. Transmission Infrared Spectroscopy of Ammonia Borane J. Undergrad. Res. 2012, 5, $1-5$.

[38] Harrick, N. J. Internal Reflection Spectroscopy; Interscience: New York, 1967.

[39] Biliškov, N. Determination of Optical Constants in the Mid-Infrared Spectral Range by use of the Attenuated Total Reflection Method Kem. Ind. 2010, 59, 11-18.

[40] Wolf, G.; Baumann, J.; Baitalow, F.; Hoffmann, F. Calorimetric Process Monitoring of Thermal Decomposition of BNH Compounds Thermochim. Acta 2000, 343, 19 - 25.

[41] Davis, B. L.; Rekken, B. D.; Michalczyk, R.; Garner, III, E. B.; Dixon, D. A.; Kalviri, H.; Baker, R. T.; Thorn, D. L. Lewis Base Assisted BH Bond Redistribution in Borazine and Polyborazylene Chem. Commun. 2013, 49, 9095-9097.

[42] Goubeau, J.; Ricker, E. Borinhydrazin und seine Pyrolyseprodukte Z. Anorg. Allg. Chem. 1961, 310, $123-142$.

[43] Sawodny, W.; Goubeau, J. Schwingungsspektren und Kraftkonstanten einiger Verbindungen des Typs X3ZNR3 Z. Phys. Chem. 1965, 44, 227-241. 
[44] Hess, N. J.; Bowden, M. E.; Parvanov, V. M.; Mundy, C.; Kathmann, S. M.; Schenter, G. K.; Autrey, T. Spectroscopic Studies of the Phase Transition in Ammonia Borane: Raman Spectroscopy of Single Crystal NH3BH3 as a Function of Temperature from 88 to 330 K J. Chem. Phys. 2008, 128, 034508.

[45] Plumley, J. A.; ; Evanseck, J. D. Covalent and Ionic Nature of the Dative Bond and Account of Accurate Ammonia Borane Binding Enthalpies J. Phys. Chem. A 2007, 111, 13472-13483.

[46] Bowden, M.; Heldebrant, D. J.; Karkamkar, A.; Proffen, T.; Schenter, G. K.; Autrey, T. The Diammoniate of Diborane: Crystal Structure and Hydrogen Release Chem. Commun. 2010, 46, 8564-8566.

[47] Fang, Z.; Luo, J.; Kang, X.; Xia, H.; Wang, S.; Wen, W.; Zhou, X.; Wang, P. Facile Solid-Phase Synthesis of the Diammoniate of Diborane and its Thermal Decomposition Behavior Phys. Chem. Chem. Phys. 2011, 13, 7508-7513.

[48] Baitalow, F.; Baumann, J.; Wolf, G.; Jaenicke-Rössler,; Leitner, G. Thermal Decomposition of BNH Compounds Investigated by Using Combined Thermoanalytical Methods Thermochim. Acta 2002, 391, 159-168.

[49] Richard, R. M.; Ball, D. W. G2, G3, and Complete Basis Set Calculations of the Thermodynamic Properties of Aminoborane, Diaminoborane, and Triaminoborane J. Mol. Struct. Theochem 2007, 823, 6 - 15.

[50] "NIST Chemistry WebBook", http://webbook.nist.gov/cgi/cbook. cgi?Name=borazine\&Units=SI\& $\mathrm{CMS}=$ on, Accessed: 2016-06-13.

[51] Meisalo, V.; Inkinen, O. An X-Ray Diffraction Analysis of Potassium Bromide Acta Cryst. 1967, 22, 58-65.

Table 1 Thermally induced processes as observed by TG/DTA measurements (Fig. 2).

\begin{tabular}{lcccccc}
\hline Process & \multicolumn{2}{c}{ air } & \multicolumn{2}{c}{$\mathbf{1}$} & \multicolumn{2}{c}{$3^{a}$} \\
& $t\left({ }^{\circ} \mathrm{C}\right)$ & $\Delta m(\%)$ & $t\left({ }^{\circ} \mathrm{C}\right)$ & $\Delta m(\%)$ & $t\left({ }^{\circ} \mathrm{C}\right)$ & $\mathrm{N}_{2}$ \\
& 114 & - & 114 & - & 110 & - \\
\hline melting & $107-129$ & 16.55 & $107-129$ & 16.55 & $101-133$ & 6 \\
1st step & $133-171$ & 9.9 & $133-185$ & 25 & \multicolumn{2}{c}{ not observed } \\
2nd step & $>171$ & 2.3 & not observed & $171-222$ & 1 \\
adsorption & $>171-222$ & & & \\
\hline
\end{tabular}

${ }^{a}$ Values with respect of mass of $\mathrm{AB}$. 
Table 2 Comparison of room-temperature IR spectra of the systems $\mathbf{1}$ - $\mathbf{3}$. Relative intensities are denoted by symbols as follows: $\mathrm{w}=\mathrm{weak}$, $\mathrm{m}$ $=$ medium, $\mathrm{s}=$ strong, $\mathrm{v}=$ very.

\begin{tabular}{|c|c|c|c|c|c|c|}
\hline \multirow[b]{2}{*}{1} & \multicolumn{2}{|l|}{ This study } & \multicolumn{2}{|c|}{ Literature } & \multirow[b]{2}{*}{ Assignation $^{a}$} & \multirow[b]{2}{*}{ Symmetry } \\
\hline & 2 & 3 & $\mathbf{I R}^{36}$ & $\operatorname{Raman}^{44}$ & & \\
\hline $3307 \mathrm{~s}$ & $3318 \mathrm{~s}$ & $3309 \mathrm{~s}$ & 3309 & 3316 & $v(\mathrm{NH})$ & $E$ \\
\hline $3250 \mathrm{~m}$ & $3252 \mathrm{~m}$ & $3254 \mathrm{~m}$ & 3183 & 3250 & $v(\mathrm{NH})$ & $A_{1}$ \\
\hline $3194 \mathrm{w}$ & $3198 \mathrm{w}, \mathrm{sh}$ & & & 3176 & overtone & \\
\hline $2345 \mathrm{sh}$ & $2384 \mathrm{sh}$ & $2376 \mathrm{sh}$ & & 2375 & & \\
\hline $2317 \mathrm{~s}$ & $2332 \mathrm{~s}$ & $2323 \mathrm{~s}$ & 2316 & 2328 & $v(\mathrm{BH})$ & $E$ \\
\hline $2278 \mathrm{~s}$ & $2280 \mathrm{~m}$ & & 2285 & 2279 & $v(\mathrm{BH})$ & $A_{1}$ \\
\hline $2217 \mathrm{~m}$ & $2219 \mathrm{w}$ & $2208 \mathrm{~m}$ & & & & \\
\hline $2117 \mathrm{w}$ & $2120 \mathrm{w}$ & & & & & \\
\hline $1600 \mathrm{~m}$ & $1607 \mathrm{~m}$ & $1600 \mathrm{~m}$ & 1600 & 1600 & $\delta\left(\mathrm{NH}_{3}\right)$ & $E$ \\
\hline 1444 vw & & & & 1450 & overtone & \\
\hline $1385 \mathrm{vw}$ & & & & & & \\
\hline $1373 \mathrm{~m}$ & $1379 \mathrm{~s}$ & $1375 \mathrm{~s}$ & & 1357 & $\delta\left(\mathrm{NH}_{3}\right)$ & $A_{1}$ \\
\hline $1155 \mathrm{~s}$ & $1163 \mathrm{~s}$ & $1156 \mathrm{~s}$ & 1175 & 1155 & $\delta\left(\mathrm{BH}_{3}\right)$ & $A_{1}^{b}$ \\
\hline $1056 \mathrm{~s}$ & $1066 \mathrm{~m}$ & $1061 \mathrm{~s}$ & 1026 & 1065 & $\rho(\mathrm{NBH})$ & $E^{c}$ \\
\hline 797 vw & $797 \mathrm{vw}$ & & & 800 & $v(\mathrm{BN})^{d}$ & $A_{1}$ \\
\hline $782 \mathrm{w}$ & $782 \mathrm{w}$ & $783 \mathrm{w}$ & 787 & 784 & $v(\mathrm{BN})^{e}$ & $A_{1}$ \\
\hline $728 \mathrm{w}$ & $727 \mathrm{w}$ & $727 \mathrm{w}$ & & 727 & $\rho\left(\mathrm{BH}_{3}\right)$ & $E$ \\
\hline
\end{tabular}

\footnotetext{
${ }^{a}$ According to ${ }^{36,42-44}$

${ }^{b}$ According to Goubeau and Sawodny, symmetry of this vibration is $E^{42,43}$, while for Taylor it is $A_{1}{ }^{36}$. Hess recognises by Raman spectroscopy two resolved bands, one at $1189 \mathrm{~cm}^{-1}$ of $E$ symmetry, and another at $1155 \mathrm{~cm}^{-1}$ of $A_{1}$ symmetry ${ }^{44}$.

${ }^{c}$ According to Taylor, symmetry of the band is $A_{1}{ }^{36}$.

${ }^{d}$ Hess assigned it to $v\left({ }^{10} \mathrm{BN}\right){ }^{44}$

${ }^{e} \mathrm{Hess}$ assigned it to $v\left({ }^{11} \mathrm{BN}\right){ }^{44}$.
}

Table 3 Temperature-induced changes in IR spectra.

\begin{tabular}{|c|c|c|c|c|c|c|c|c|c|c|c|}
\hline \multicolumn{12}{|c|}{ Band positions $\left(\mathrm{cm}^{-1}\right)$} \\
\hline $1-125$ & $2-125$ & 3-125 & $1-140$ & $2-140$ & 3-140 & 1-160 & $2-160$ & $3-160$ & $1-200$ & $2-200$ & 3-200 \\
\hline- & - & - & $3437 \mathrm{vw}$ & - & - & $3437 \mathrm{~m}$ & $3440 \mathrm{w}$ & - & $3437 \mathrm{~m}$ & $3437 \mathrm{~m}$ & $3437 \mathrm{w}$ \\
\hline $3291 \mathrm{w}, \mathrm{sh}$ & - & $3291 \mathrm{~m}$ & $3292 \mathrm{~m}$ & - & - & $3279 \mathrm{~m}$ & $3270 \mathrm{~s}$ & - & $3239 \mathrm{~m}$ & $3261 \mathrm{~m}$ & - \\
\hline $3248 \mathrm{~m}$ & $3262 \mathrm{~s}$ & - & $3245 \mathrm{~m}$ & $3262 \mathrm{~s}$ & $3196 \mathrm{~m}$ & - & - & $3176 \mathrm{~m}$ & - & - & 3143 \\
\hline $2386 \mathrm{~m}$ & $2355 \mathrm{w}, \mathrm{sh}$ & - & $2386 \mathrm{~m}$ & $2358 \mathrm{~s}$ & $2383 \mathrm{w}, \mathrm{sh}$ & $2419 \mathrm{~m}$ & $2355 \mathrm{~s}$ & $2393 \mathrm{~m}$ & $2470 \mathrm{w}$ & $2356 \mathrm{~s}$ & $2495 \mathrm{w}$ \\
\hline $2284 \mathrm{~s}$ & $2291 \mathrm{~m}$ & $2336 \mathrm{~m}$ & $2292 \mathrm{~s}$ & $2295 \mathrm{~m}$ & $2305 \mathrm{~m}$ & $2335 \mathrm{w}$ & $2295 \mathrm{~m}$ & - & - & $2296 \mathrm{~s}$ & - \\
\hline $1560 \mathrm{~m}$ & $1600 \mathrm{w}$ & $1612 \mathrm{w}$ & $1557 \mathrm{~m}$ & $1557 \mathrm{w}$ & $1558 \mathrm{~m}$ & - & - & - & - & - & - \\
\hline $1386 \mathrm{~m}$ & $1407 \mathrm{~m}$ & $1373 \mathrm{~s}$ & $1410 \mathrm{vs}$ & $1415 \mathrm{~s}$ & $1400 \mathrm{~m}$ & $1380 \mathrm{vs}$ & $1419 \mathrm{~s}$ & $1415 \mathrm{~s}$ & 1332 vs & 1427 vs & 1379 vs \\
\hline $1154 \mathrm{vs}$ & $1165 \mathrm{~m}$ & $1162 \mathrm{~s}$ & $1150 \mathrm{vs}$ & $1163 \mathrm{~m}$ & $1150 \mathrm{~s}$ & $1121 \mathrm{vs}$ & 1139 vs & $1164 \mathrm{~m}$ & 1096 vs & $1172 \mathrm{~m}$ & $1163 \mathrm{~m}$ \\
\hline $860 \mathrm{~m}$ & - & - & $900 \mathrm{~m}$ & - & $850 \mathrm{w}$ & $900 \mathrm{~s}$ & 870 w & $870 \mathrm{w}$ & $896 \mathrm{~m}$ & $906 \mathrm{w}$ & $895 \mathrm{~m}$ \\
\hline - & - & - & $712 \mathrm{~m}$ & $710 \mathrm{w}$ & - & $702 \mathrm{vs}$ & $710 \mathrm{~m}$ & $720 \mathrm{w}$ & 713 vs & $744 \mathrm{~m}$ & $693 \mathrm{~m}$ \\
\hline
\end{tabular}


Table 4 Temperature ranges ( $99 \%$ of the area under fitted Lorentzian curve) (in ${ }^{\circ} \mathrm{C}$ ) in which the gaseous species are released from $\mathbf{1}$ and $\mathbf{3}$.

\begin{tabular}{|c|c|c|c|c|c|c|c|}
\hline \multirow{3}{*}{$m / z$} & \multirow{3}{*}{ assignation } & \multicolumn{3}{|c|}{$1^{\text {st }}$ step } & \multicolumn{3}{|c|}{$2^{\text {nd }}$ step } \\
\hline & & \multirow{2}{*}{$\begin{array}{c}\mathrm{N}_{2} \\
\mathbf{1}\end{array}$} & \multicolumn{2}{|c|}{ air } & \multirow{2}{*}{$\begin{array}{c}\mathrm{N}_{2} \\
\mathbf{1}\end{array}$} & \multicolumn{2}{|c|}{ air } \\
\hline & & & 1 & 3 & & 1 & 3 \\
\hline 2 & $\mathrm{H}_{2}$ & $100-132$ & $105-137$ & $95-128$ & $110-186$ & $123-185$ & $128-205$ \\
\hline 17 & $\mathrm{NH}_{3}$ & $107-123$ & $108-134$ & $86-130$ & $126-190$ & $122-190$ & $130-195$ \\
\hline 28 & $\mathrm{~B}_{2} \stackrel{3}{\mathrm{H}}_{6}$ & $93-129$ & $104-136$ & - & $117-165$ & $120-192$ & - \\
\hline 43 & $\mathrm{NH}_{2}\left(\mathrm{BH}_{2}-\mathrm{H}-\mathrm{BH}_{2}\right)$ & $93-124$ & $102-127$ & $58-130$ & - & - & $145-180$ \\
\hline 58 & cyclo- $\left(\mathrm{NH}_{2} \mathrm{BH}_{2}\right)_{2}$ & $91-124$ & $94-121$ & - & $132-194$ & $135-182$ & - \\
\hline 80 & cyclo- $(\mathrm{NHBH})_{3}{ }^{a}$ & $110-124$ & $114-132$ & $102-125$ & $123-185$ & $127-187$ & $130-195$ \\
\hline
\end{tabular}

${ }^{a}$ The observed signals in the $m / z=62-64 \mathrm{amu}$ and $50-55$ amu range, respectively, are due to borazine fragments. ${ }^{50}$

Table 5 Ratio of the released gaseous species from sample 1 in $\mathrm{N}_{2}$ with respect of the air atmosphere at 115 and $150^{\circ} \mathrm{C}$.

\begin{tabular}{|c|c|c|c|c|c|c|c|c|c|c|}
\hline \multirow{4}{*}{$m / z$} & \multicolumn{8}{|c|}{ EGA-MS intensity $\left(I / 10^{-9}\right)^{a}$} & \multirow{3}{*}{\multicolumn{2}{|c|}{$\begin{array}{c}I\left(1^{s t}\right) / I\left(2^{\text {nd }}\right) \\
\text { air }\end{array}$}} \\
\hline & \multicolumn{4}{|c|}{$1^{\text {st }}$ step } & \multicolumn{4}{|c|}{$2^{\text {nd }}$ step } & & \\
\hline & \multirow[b]{2}{*}{3} & ir & \multirow{2}{*}{$\begin{array}{c}\mathrm{N}_{2} \\
\mathbf{1}\end{array}$} & \multirow[b]{2}{*}{$x(\mathbf{1})^{b}$} & \multirow[t]{2}{*}{ ai } & \multirow[t]{2}{*}{ ir } & \multirow{2}{*}{$\begin{array}{c}\mathrm{N}_{2} \\
\mathbf{1}\end{array}$} & \multirow[b]{2}{*}{$x(\mathbf{1})$} & & \\
\hline & & 1 & & & & & & & 1 & 3 \\
\hline 2 & $171.8 \pm 5.9$ & $108.5 \pm 3.1$ & $118.1 \pm 2.9$ & 1.08 & $242.3 \pm 5.4$ & $180.9 \pm 10.8$ & $151.8 \pm 9.0$ & 0.84 & 0.60 & 0.71 \\
\hline 17 & $24.2 \pm 0.6$ & $20.6 \pm 1.0$ & $13.1 \pm 0.3$ & 1.57 & $8.9 \pm 1.2$ & $31.7 \pm 2.8$ & $15.9 \pm 1.0$ & 2.0 & 0.82 & 2.72 \\
\hline 28 & - & $1.1 \pm 0.1$ & $3.7 \pm 0.2$ & 0.30 & - & $1.1 \pm 0.2$ & $7.2 \pm 0.4$ & 0.15 & 0.51 & - \\
\hline 43 & $0.7 \pm 0.1$ & $0.7 \pm 0.04$ & $0.7 \pm 0.05$ & 1.00 & $0.07 \pm 0.03$ & - & - & - & - & 10.0 \\
\hline 58 & - & $0.1 \pm 0.01$ & $0.1 \pm 0.01$ & 1.00 & - & $0.1 \pm 0.01$ & $0.1 \pm 0.01$ & 1.00 & 1.00 & - \\
\hline 80 & $0.2 \pm 0.01$ & $0.6 \pm 0.1$ & $0.8 \pm 0.06$ & 0.75 & $0.1 \pm 0.03$ & $8.7 \pm 0.2$ & $6.1 \pm 0.1$ & 1.43 & 0.13 & 2.00 \\
\hline
\end{tabular}

${ }^{a}$ Area under the fitted Lorentzian bandshape function.

${ }^{b}$ For $1, I\left(\mathrm{~N}_{2}\right) / I($ air $)$ 


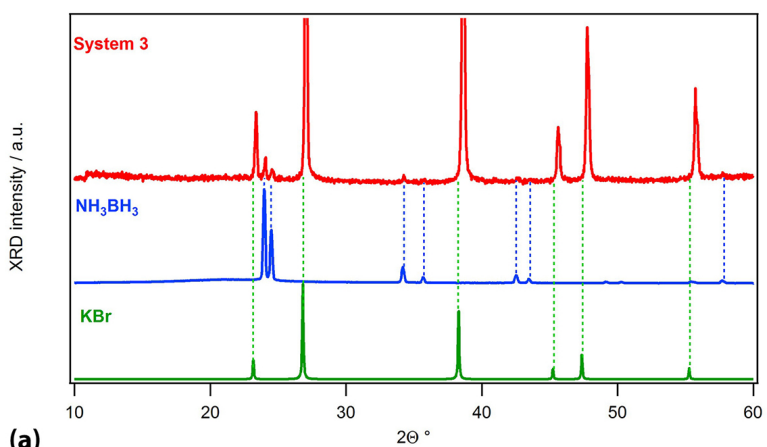

(a)

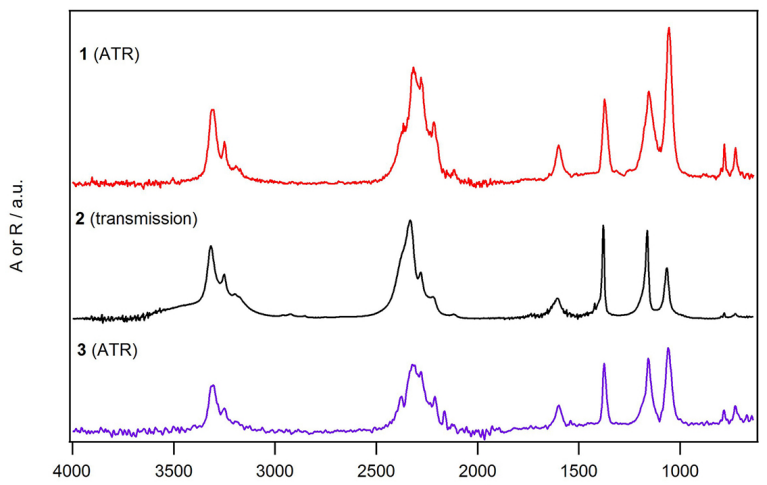

(b)



(c)

Figure 1 Comparison of the investigated systems at room temperature: (a) powder XRD pattern of system $\mathbf{3}$, as compared with $\mathrm{KBr}^{51}$ and $\mathrm{AB},{ }^{46}$ respectively; (b) IR spectra of the three investigated systems; (c) Raman spectra of $\mathbf{1}$ and $\mathbf{3}$. 


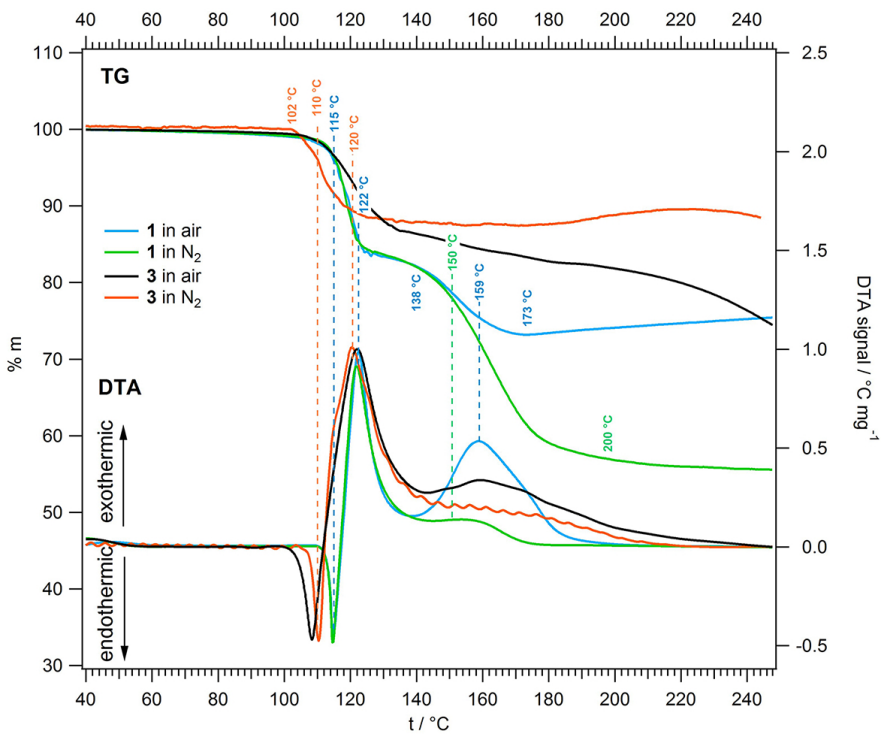

Figure 2 Comparison of TG/DTA for the system $\mathbf{1}$ (blue line) and 3, respectively. Mass loss in the TG of $\mathbf{3}$ is calculated with respect of initial mass of $\mathrm{AB}$ in the mixture. 

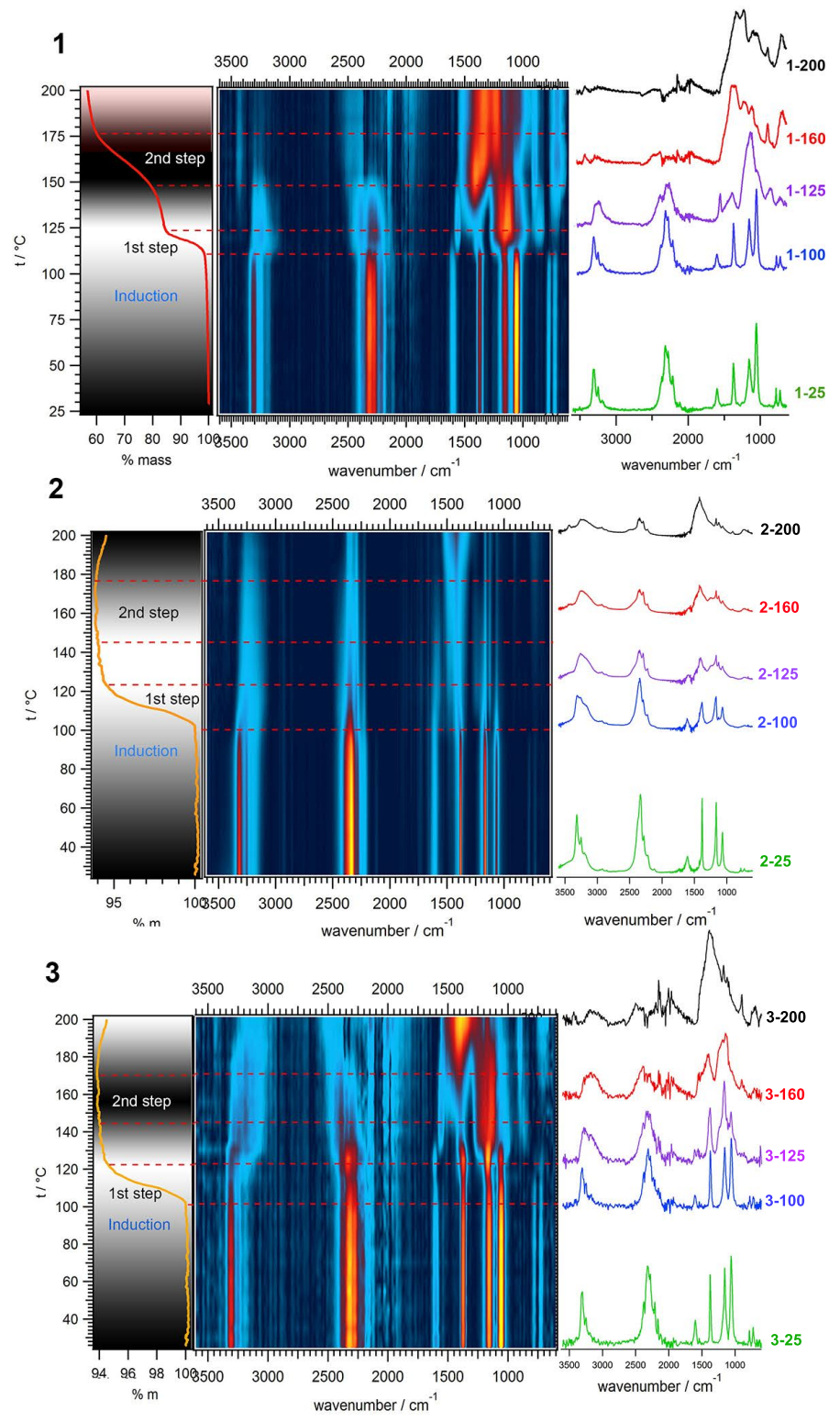

Figure 3 Comparison of variable-temperature IR spectra with TG/DTA. TG/DTA of $\mathbf{3}$ are used for comparison with IR spectra of $\mathbf{2}$. 

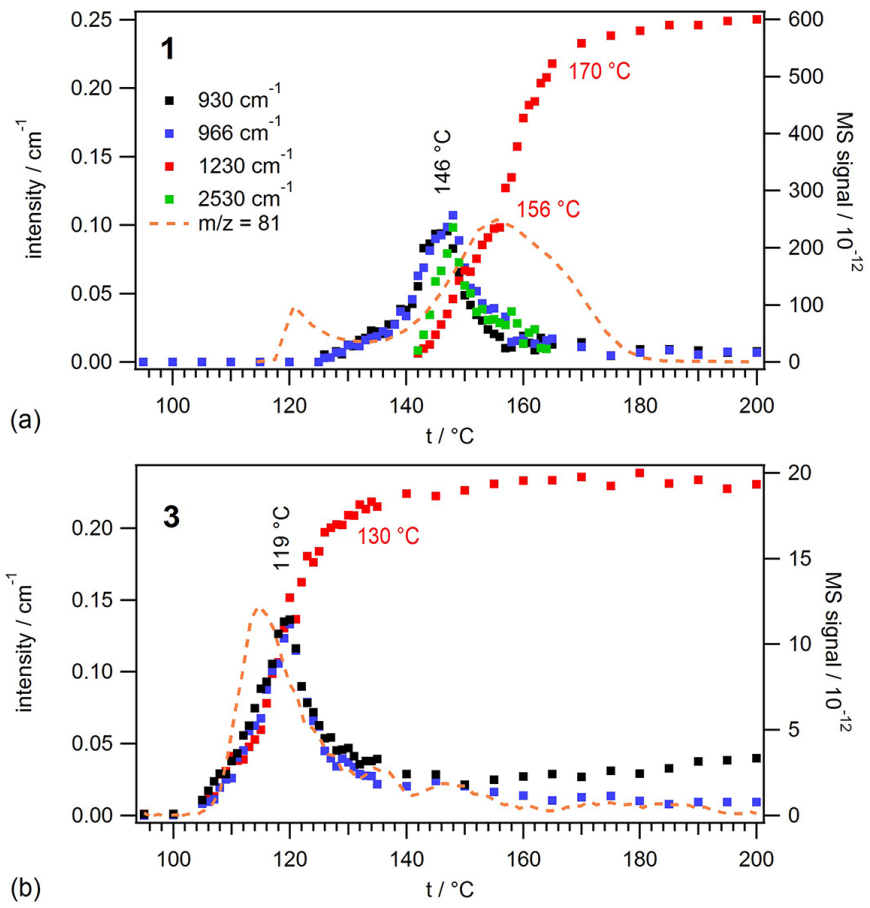

Figure 4 Temperature-induced evolution of the gas-phase species as observed by TG-IR at heating rate $2{ }^{\circ} \mathrm{Cmin}{ }^{-1}$, as compared with EGA-MS signal at $m / z=81$ of (a) 1 and (b) 3. Values are obtained by fitting the profiles to Lorentzian functions for 930,966 and $2530 \mathrm{~cm}^{-1}$ and to Gaussian function for $1230 \mathrm{~cm}^{-1}$ feature. 

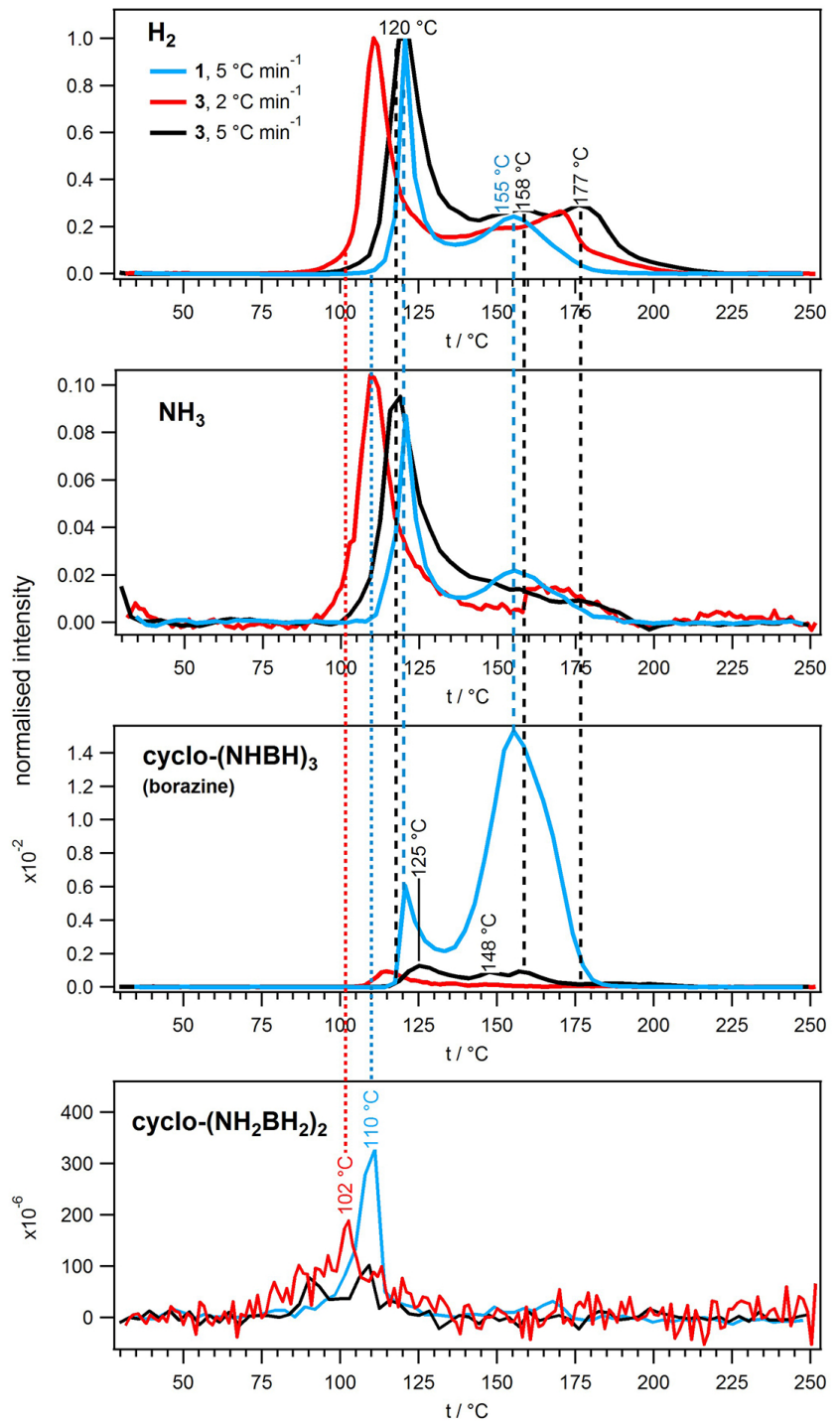

Figure 5 EGA-MS profiles of the main gaseous species released during the decomposition of $\mathbf{1}$ (blue line) and $\mathbf{3}$ (red line for $2{ }^{\circ} \mathrm{Cmin}{ }^{-1}$ and black for $5^{\circ} \mathrm{C} \mathrm{min}^{-1}$, respectively). Ionic current is normalised. $\mathrm{For}_{2}, \mathrm{NH}_{3}$ and $\mathrm{CDAB}$ temperature values are obtained by fitting the profiles to Lorentzian functions, while for borazine Gaussian function was used. Intensity values are listed in Table S6. 


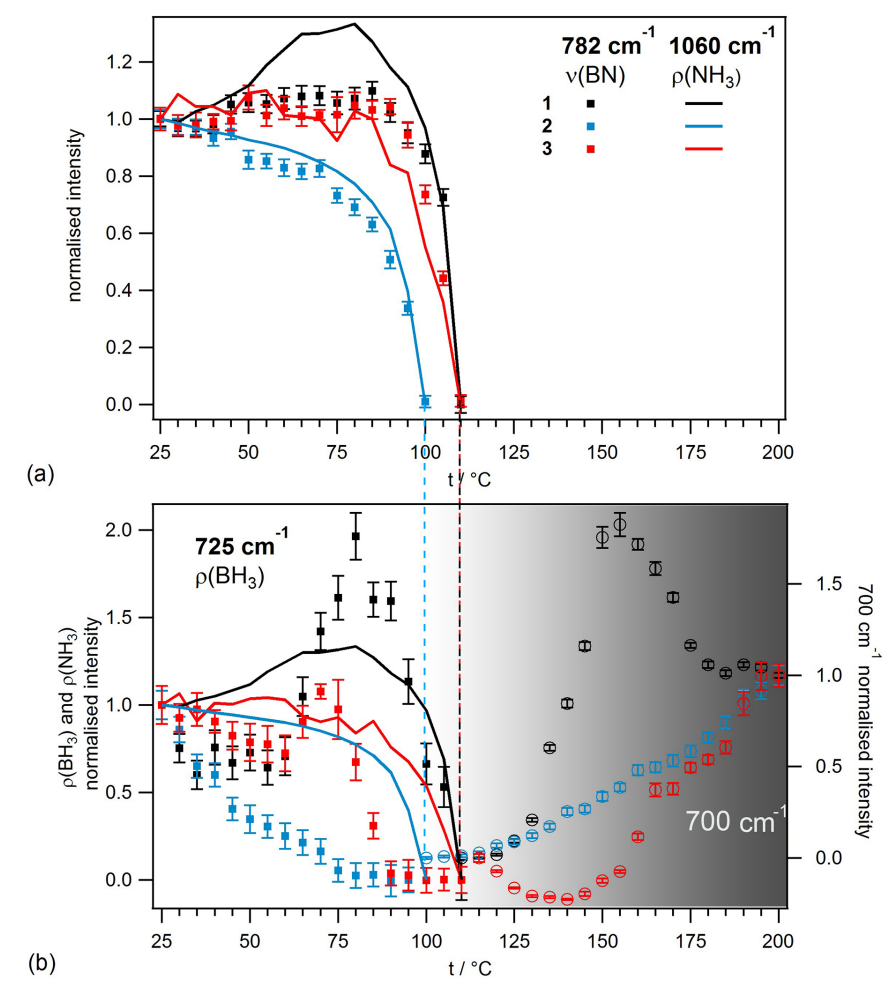

Figure 6 Temperature-induced behaviour of the normalised IR intensity $I(t)$ of $\rho\left(\mathrm{NH}_{3}\right)$ band at $1060 \mathrm{~cm}^{-1}$ (solid lines) as compared with (a) $v(\mathrm{BN})$ at $782 \mathrm{~cm}^{-1}$ and (b) $\rho\left(\mathrm{BH}_{3}\right)$ at $725 \mathrm{~cm}^{-1}$ and appearence of the feature at $700 \mathrm{~cm}^{-1}$ (open circles in grey part of the plot). Intensities are obtained by fitting of the $800-700 \mathrm{~cm}^{-1}$ region to Lorentzian functions. Normalisation of $I(t)$ curves was done by dividing all values with the value of the starting points of 782 and $725 \mathrm{~cm}^{-1}$ band, respectively. The values of final points are in both cases very small and they were set to 0 by subtraction. Normalisation of the $700 \mathrm{~cm}^{-1}$ band was done in opposite way since intensity of this band increases with temperature. Error bars represent $\pm 1 \sigma$ of the fit. 

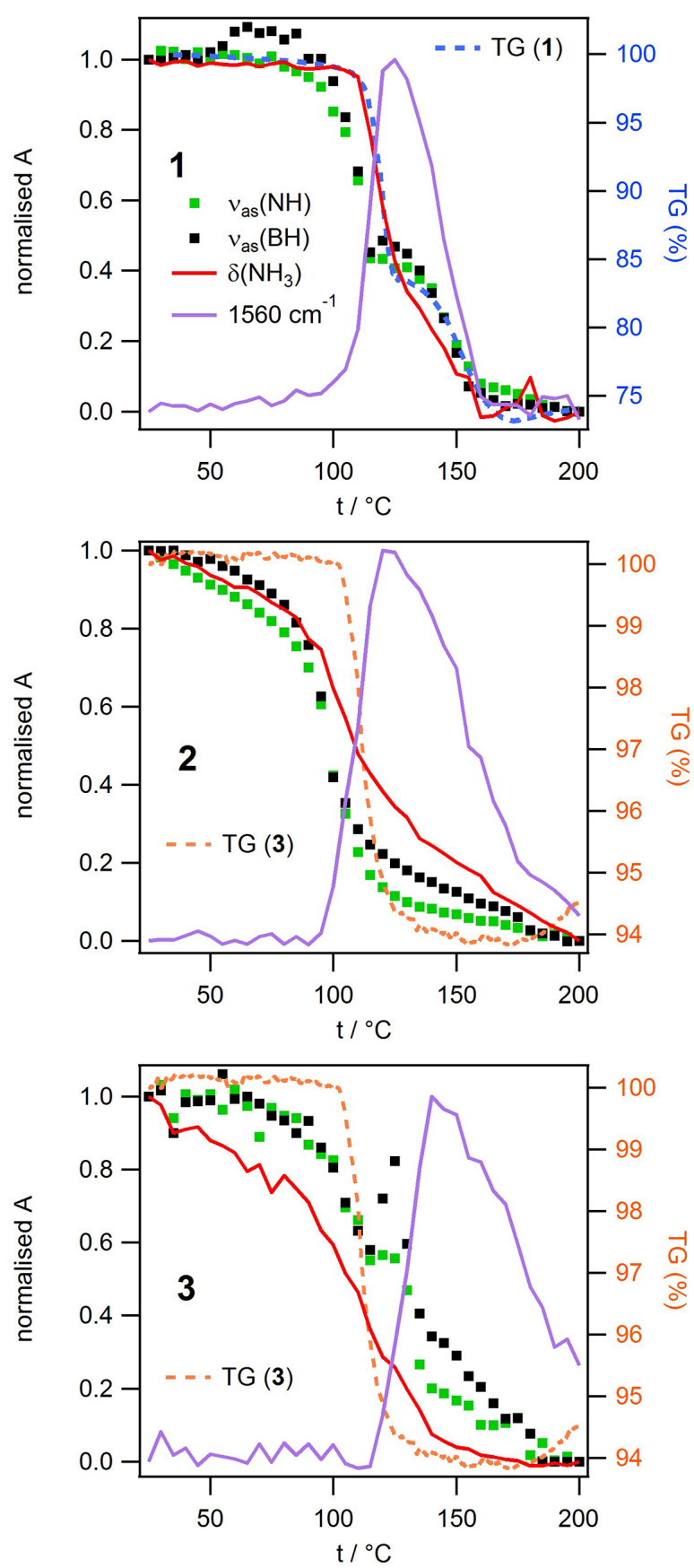

Figure 7 Behaviour of the $v_{\mathrm{s}}(\mathrm{NH}), v_{\mathrm{as}}(\mathrm{NH})$ and $\delta\left(\mathrm{NH}_{3}\right)$ IR spectral features as compared with TG curves for corresponding systems. The values are for IR intensities are obtained by fitting the spectral envelopes to Lorentzian functions, and normalised with respect to maxima of the individual curves. 

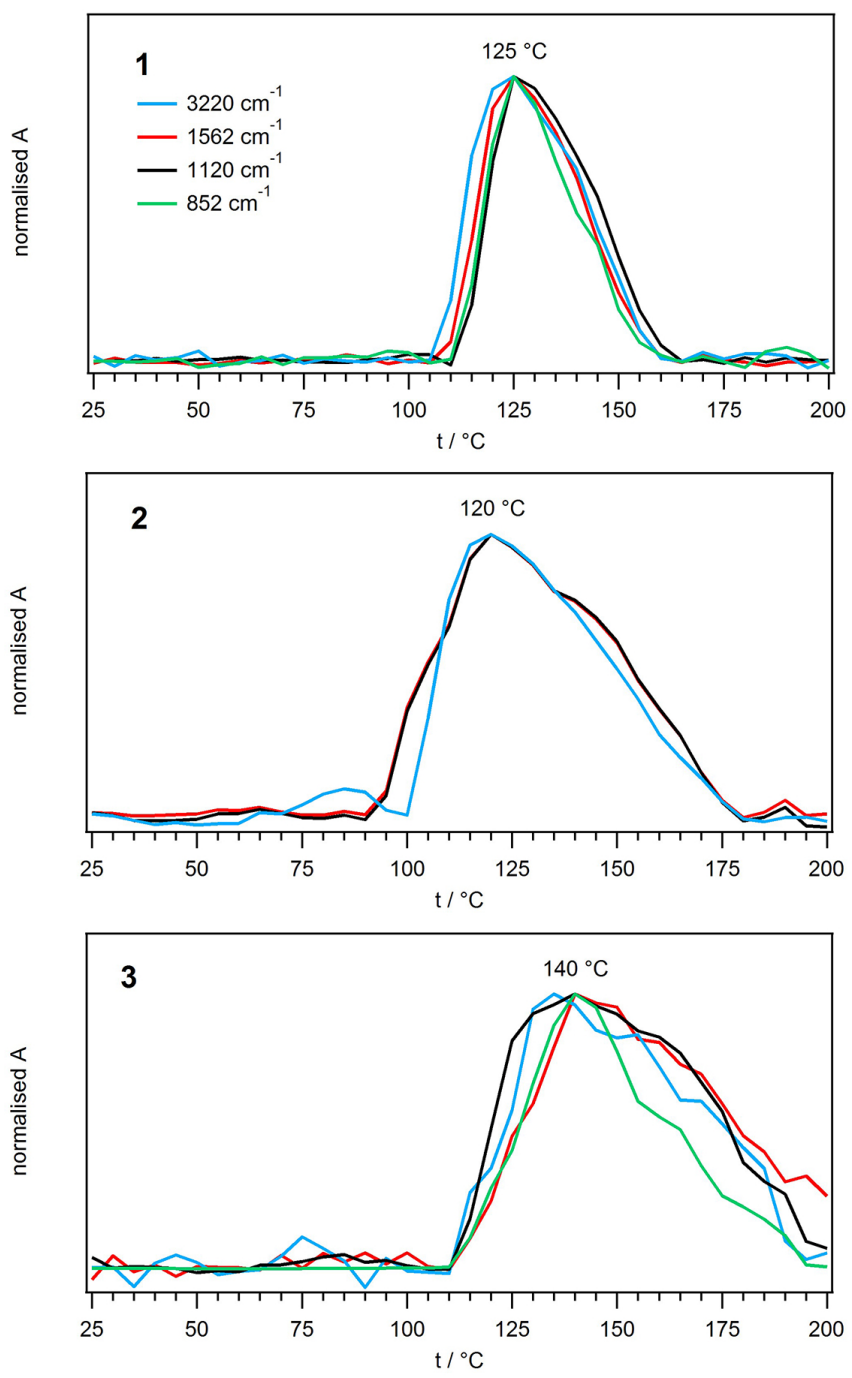

Figure 8 Behaviour of the IR spectral bands due to the PAB species. 